\section{Implications of Carbon Regulation for Green Power Markets}

Technical Report NREL/TP-640-41076 April 2007

Lori Bird

National Renewable Energy Laboratory

Ed Holt

Ed Holt \& Associates Inc.

Ghita Carroll, Research Participant National Renewable Energy Laboratory

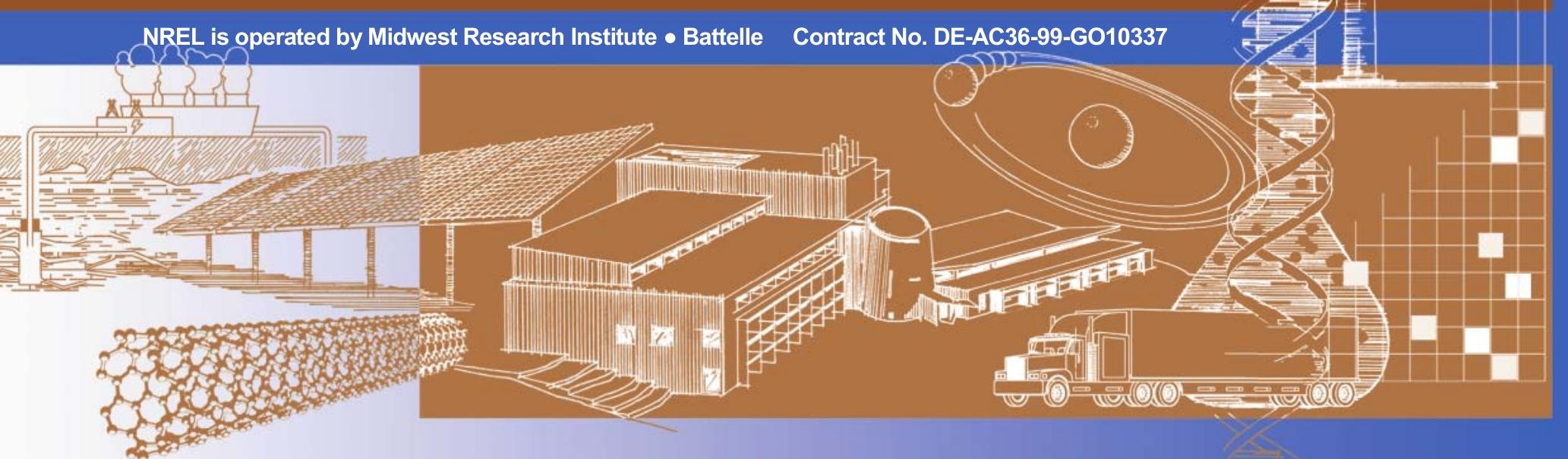




\section{Implications of Carbon Regulation for Green Power Markets}

Lori Bird

National Renewable Energy Laboratory

Ed Holt

Ed Holt \& Associates Inc.

Ghita Carroll, Research Participant National Renewable Energy Laboratory

Prepared under Task No. ASG6.1005 


\section{NOTICE}

This report was prepared as an account of work sponsored by an agency of the United States government. Neither the United States government nor any agency thereof, nor any of their employees, makes any warranty, express or implied, or assumes any legal liability or responsibility for the accuracy, completeness, or usefulness of any information, apparatus, product, or process disclosed, or represents that its use would not infringe privately owned rights. Reference herein to any specific commercial product, process, or service by trade name, trademark, manufacturer, or otherwise does not necessarily constitute or imply its endorsement, recommendation, or favoring by the United States government or any agency thereof. The views and opinions of authors expressed herein do not necessarily state or reflect those of the United States government or any agency thereof.

Available electronically at http://www.osti.gov/bridge

Available for a processing fee to U.S. Department of Energy and its contractors, in paper, from:

U.S. Department of Energy

Office of Scientific and Technical Information

P.O. Box 62

Oak Ridge, TN 37831-0062

phone: 865.576 .8401

fax: 865.576 .5728

email: mailto:reports@adonis.osti.gov

Available for sale to the public, in paper, from:

U.S. Department of Commerce

National Technical Information Service

5285 Port Royal Road

Springfield, VA 22161

phone: 800.553.6847

fax: 703.605.6900

email: orders@ntis.fedworld.gov

online ordering: http://www.ntis.gov/ordering.htm 


\section{Acknowledgments}

This work was funded by the U.S. Department of Energy's (DOE) Office of Energy Efficiency and Renewable Energy (EERE). The authors wish to thank Linda Silverman and the EERE renewable energy technology programs for their support of this work. The authors also wish to thank the following individuals for providing information and valuable perspectives for this report: Mark Draeck, IT Power Ltd.; Matt Freedman, TURN; Jan Hamrin and Jennifer Martin, Center for Resource Solutions (CRS); Sonia Hamel, Massachusetts Office for Commonwealth Development; Craig Hanson and Samantha Putt del Pino, World Resources Institute; Kjell Olav Kristiansen, Point Carbon; Michael McCormick, California Climate Action Registry; Joanne Morin, New Hampshire Department of Environmental Services; Lainie Motamedi, California Public Utilities Commission; Peter Niermeijer, RECS International Secretariat; Hampton Newsome, Janice Podoll Frankel, and James Hilger, Federal Trade Commission; Gabe Petlin, 3 Phases Energy; Thorsten Schneiders, E.ON Energie AG. The authors also wish to thank Jane Pater for research support and Michelle Kubik of the National Renewable Energy Laboratory (NREL) for editorial support. Finally, the authors appreciate the thoughtful review comments provided by the following individuals:

Derik Broekhoff, World Resources Institute

Bob Grace, Sustainable Energy Advantage

Rob Harmon, Bonneville Environmental Foundation

Angela Leontis, Chicago Climate Exchange

Dan Lieberman, CRS

Rick Morgan, District of Columbia Public Service Commission

Tom Rawls, THR Associates

Liz Salerno, American Wind Energy Association

Blair Swezey and Laura Vimmerstedt, NREL

Christopher Sherry, New Jersey Department of Environmental Protection

Ryan Wiser, Lawrence Berkeley National Laboratory

Additional information on green power markets can be found on DOE's Green Power Network Web site (http://www.eere.energy.gov/greenpower/). 


\section{Table of Contents}

\section{$\underline{\text { Page }}$}

Executive Summary 1

Impact of Cap and Trade on Renewable Energy Markets 1

Emerging Carbon Markets in the United States and Europe 4

Policy Options for Enabling Renewable Energy Claims 5

$\begin{array}{ll}\text { Conclusion } & 7\end{array}$

1.0 Introduction $\quad 9$

2.0 Relationship Between Voluntary Renewable Energy Markets and Carbon 11

$\begin{array}{ll}\text { Climate Change as Motivator for Green Power Purchasers } & 11\end{array}$

Marketing Renewable Energy and Climate Change Benefits 16

What Kinds of Claims Can Be Made About GHG Benefits Currently 19

3.0 Impact of Carbon Regulation on Renewable Energy Markets 22

Effect of Cap and Trade on Marketing Claims 22

Effect on Price and Demand for Renewable Energy in Voluntary

$\begin{array}{ll}\text { Markets } & 27\end{array}$

Effect on Compliance REC Markets $\quad 30$

Effect of Receiving Allowances but Selling Them Separately from the REC $\quad 31$

4.0 Emerging Carbon Markets in the United States 33

Regional Greenhouse Gas Initiative (RGGI) 34

California "Global Warming Solutions Act" and Load-Based GHG Cap

Chicago Climate Exchange 41

$\begin{array}{ll}\text { European Union (EU) } & 44\end{array}$ 
5.0 Policy Design Options 46

Set-aside Allocations to Renewable Generators 46

Output-based Allocations to Renewable Generators 48

$\begin{array}{ll}\text { Load-Based Cap } & 49\end{array}$

Reduce the Cap to Account for Renewable Energy Demand 51

Retire Allowances on Behalf of Renewable Energy Sales 52

6.0 Summary and Conclusions $\quad 55$

$\begin{array}{ll}\text { References } & 58\end{array}$ 


\section{Executive Summary}

Today, voluntary renewable energy markets serve an important role by empowering consumers to affect the resources used to meet their electricity needs as well as educating consumers about the benefits of renewable energy. In recent years, voluntary purchases of renewable energy by residential, business, and institutional consumers have increased considerably. For example, in 2005, sales of renewable energy in voluntary markets increased nearly $40 \%$ following an increase of more than $60 \%$ during 2004 . Voluntary renewable energy markets appear poised to grow substantially, particularly because of nonresidential demand; however, the emerging regulation of carbon dioxide $\left(\mathrm{CO}_{2}\right)$ emissions has implications for the future growth and viability of voluntary renewable energy markets.

While there are a variety of reasons why consumers make voluntary purchases of renewable energy, greenhouse gas (GHG) benefits provide important motivation, particularly for nonresidential consumers who often purchase renewable energy to meet GHG emissions-reduction goals or make environmental claims. Carbon regulation, particularly via cap and trade, has the potential to affect the types of claims that marketers and purchasers can make with respect to the environmental benefits of renewable energy purchases, depending on how the policy is implemented. We focus on the implications of cap-and-trade programs on renewable energy markets for two reasons: Some states are beginning to develop such programs, and there is significant policy precedent for using cap and trade at the federal level to control emissions of sulfur dioxide $\left(\mathrm{SO}_{2}\right)$; oxides of nitrogen $\left(\mathrm{NO}_{\mathrm{x}}\right)$; and, most recently, mercury.

While carbon regulation is likely to affect renewable energy development more broadly, this paper focuses primarily on issues pertaining to voluntary renewable energy markets. First, the paper examines the extent to which GHG benefits motivate consumers to make voluntary renewable energy purchases and the claims that large commercial and institutional consumers currently make regarding their purchases. Next, the paper looks at the potential impacts of carbon regulation on future claims, as well as on demand for and the price of renewable energy certificates (RECs), and the use of RECs in multiple markets (disaggregation of attributes). Then, it describes carbon regulation programs under development in the Northeast and California, and how these might affect renewable energy markets in these regions, as well as the potential interaction between voluntary renewable energy markets and voluntary carbon markets, such as the Chicago Climate Exchange (CCX). The paper also briefly summarizes the experience in the European Union, where carbon is already regulated. Finally, the paper presents policy options for policymakers and regulators to consider in designing carbon policies to enable carbon markets and voluntary renewable energy markets to work together.

\section{Impact of Cap and Trade on Renewable Energy Markets}

A carbon cap-and-trade system sets a maximum level (cap) for carbon emissions. To achieve compliance with the capped emissions level, allowances to emit carbon (1 ton per allowance) are created and distributed, with the total number of allowances summing to 
the level of the cap. The allowances can be bought and sold (traded) in the market. Some market participants will need to purchase allowances to cover excess emissions, while other market participants will sell or retire allowances if they are not needed for compliance. Cap-and-trade programs often are designed to achieve greater reductions over time, so the cap may be lowered in subsequent years.

Traditionally, in the electric power industry, emissions allowances have been allocated only to emitting power plants, i.e., those that burn fossil fuels, based on historic emissions or on the heat content of the fuels burned. Other possible approaches are to allocate allowances in proportion to a generator's share (output-based) or supplier's share (load-based) of the overall electricity market, regardless of how the electricity is generated, or to auction some or all of the allowances to the highest bidders.

In general, renewable energy does benefit from carbon cap-and-trade programs because compliance with the cap will increase the costs of fossil fuel generation, which will improve the cost-effectiveness of renewables. In addition, such programs may provide an incentive to capped entities to use renewable energy to meet future load growth without exceeding the cap. The level of the cap will determine the magnitude of the incentive provided for renewables.

However, cap-and-trade programs can also impact the ability of renewable energy generation to affect overall $\mathrm{CO}_{2}$ emissions levels, depending on the design of the program. If renewable generation sources are not accounted for under the cap (through the retirement of allowances or in setting the level of the cap), then they will not affect the overall level of $\mathrm{CO}_{2}$ emissions, and purchasers of renewable energy have no basis for claiming overall emission reductions.

For example, if a new wind energy facility generates electricity at a time that causes a fossil fuel facility to back down, the emitting fossil fuel facility will generate less electricity and consequently emit less $\mathrm{CO}_{2}$, enabling it to sell any excess allowances it has to another facility. The other facility will avoid controlling emissions and emit more $\mathrm{CO}_{2}$, bringing total emissions back up to the level of the cap. Similarly, if the wind generation facility offsets the need for a new fossil fuel plant, then existing emitters will not need to control emissions for the zero-emitting wind plant to come online. In either case, i.e., whether the renewable energy plant displaces an existing or new fossil plant, the result is the same - the renewable energy facility does not reduce the overall level of carbon emissions. Rather, the level of emissions is established by the cap.

\section{Effect on Renewable Energy Marketing Claims}

If a renewable energy purchase results in the retirement or reduction of carbon emission allowances, then, by definition, the generation and use of renewable energy should result in real emission reductions and strengthen environmental marketing claims. What benefits can marketers and purchasers claim if they don't retire an allowance or if the cap is not adjusted to account for current and future renewable energy generation? If renewable energy does not result in a direct carbon reduction, the simplest claim that generators or marketers could make is that the renewable energy is "emission-free" or 
"pollution-free." This is the general approach to marketing renewable energy in Europe, because carbon and REC markets operate independently. However, such claims might imply to consumers that they are helping to reduce emissions.

In addition, a marketer might make a claim that a purchase would reduce "your emissions footprint." Such claims might be feasible because a company that buys renewable energy would improve the emissions profile of its power purchases even though overall systemwide emissions of carbon would not be reduced. However, companies may resist the idea of making such claims, because overall carbon levels would be unaffected, and this could be questioned by consumer-protection agencies as deceptive.

\section{Effect on Renewable Energy Demand}

With the introduction of carbon regulation, renewable energy markets will gain an additional layer of complexity, affecting supply and demand. The form of carbon regulations will determine the magnitude of the impacts on REC markets. If marketers and purchasers cannot make clear claims of environmental benefits as a result of carbon regulation, it could reduce the purchasing motivation of nonresidential consumers, in particular, which would negatively affect future voluntary market growth. Because the lack of GHG emissions from renewable energy sources is generally considered to be the most significant environmental benefit of these technologies, the inability to affect emissions levels will likely reduce voluntary market demand for renewable energy and put downward pressure on the price of RECs.

Consumers interested in reducing carbon emissions levels and making associated claims could purchase and retire carbon allowances in conjunction with their renewable energy or REC purchase. However, this would add cost to the renewable energy product or reduce the amount of revenue that would go to support renewable energy generation, which would reduce the ability of voluntary markets to support new renewable energy development. Consumers could also simply purchase and retire allowances and skip the renewable energy component altogether, again reducing demand.

\section{Effect on Compliance Markets}

Carbon regulation also has important implications for renewable energy compliance markets. With the development of carbon markets, states will need to determine whether RECs used for state renewable portfolio standard (RPS) compliance must include (and retire) carbon allowances, if allowances are granted to renewables. States might want to consider the objective of the RPS in making this decision. If the objective of the RPS is to achieve emission reductions, this can be achieved by retiring allowances with the REC or considering the RPS in setting the level of the cap. Some states are explicit about whether allowances must be retired with a REC used for RPS compliance; but, as might be expected, states have taken different positions. For example, both New York and Colorado insist that emissions benefits and allowances, if any, be retired for RPS compliance. Delaware does not require retirement of allowances with a REC, and Pennsylvania has proposed similar rules. 


\section{Emerging Carbon Markets in the United States and Europe}

Carbon markets are beginning to take form in the United States as a number of states have initiated their own policies and programs, and others are considering action. The design of these programs will affect voluntary renewable energy markets. In this report, we focus on the leading efforts to date and discuss their potential impacts on renewable energy markets. We also briefly discuss the experience in Europe, where carbon is already regulated.

Regional Greenhouse Gas Initiative. The Regional Greenhouse Gas Initiative (RGGI) is a regional cap-and-trade system for reducing GHG emissions of participating Northeast states. To date, nine states have committed to participate, while several others are considering joining. Implementation of RGGI will begin in January 2009, at which point the states have agreed to cap regional $\mathrm{CO}_{2}$ emissions at current levels through 2015; and, thereafter, reduce emissions by $2.5 \%$ each year, for a $10 \%$ total reduction by the end of 2018. RGGI will begin by capping $\mathrm{CO}_{2}$ emissions from electricity-generating sources of $25 \mathrm{MW}$ or larger.

The structure of the RGGI program raises issues for the ability of renewable energy sources to reduce GHG emissions, depending on how states choose to implement it. States have significant discretion in determining how to allocate allowances. At the time of writing, a number of states are leaning toward using an auction, in which market entities would bid to purchase allowances. In this case, renewable energy generators and marketers would have to pay for allowances in order to achieve GHG reductions. However, the RGGI Model Rule does permit the retirement of allowances on behalf of consumers who make voluntary purchases of renewable energy. This is discussed in more detail in the RGGI section in Chapter 4.

California Load-Based Cap and Global Warming Solutions Act. In February 2006, the California Public Utilities Commission (CPUC) issued a decision stating its intent to establish a load-based cap (a cap placed on load-serving entities rather than individual generators) for the state's three investor-owned utilities and nonutility load-serving entities (LSEs). Subsequently, in August 2006, the California State Legislature adopted the Global Warming Solutions Act (AB32), which requires a reduction of statewide GHG emissions from electricity consumption and other "significant" sources to 1990 levels by 2020, beginning in 2012. AB32 now acts as the umbrella regulation for the CPUC's effort to create a load-based cap and other efforts to meet the AB32 targets. Because it is still early in the design process for California's GHG regulatory systems, it is difficult to determine how much of an influence these programs will have on renewable energy markets. The issue of whether renewable energy generators will be able to demonstrably and directly reduce GHG emissions will depend on the policy structure. Regulators will need to address whether voluntary purchases would be in addition to reductions achieved by the cap. If the policy is designed so that a renewable energy source that has sold off its RECs in the voluntary market would result in system power that needs an allowance, then a voluntary purchase would have the effect of reducing emissions below the cap. 
Chicago Climate Exchange. Created in 2000, the Chicago Climate Exchange (CCX) is a voluntary but legally binding GHG emissions registry and trading market. Under CCX, participating entities - which include municipalities, states, universities, power providers, agricultural organizations, and large corporations - commit to reducing their GHG emissions and can buy and sell eligible emission reductions through the exchange. In Phase I, each member committed to reducing emissions by $1 \%$ annually below an established baseline from 2003-2006. In Phase II, all members must reduce emissions 6\% below their baselines by 2010 .

CCX interacts with renewable energy markets on a number of levels. First, it provides another voluntary market for the output of renewable energy generation, because renewables are eligible to create offsets under CCX. However, few, if any, renewable energy projects have been used for offsets to date, because other voluntary REC markets have provided greater revenues. Second, CCX facilitates a certain degree of competition for renewable energy from other types of carbon reduction projects.

European Union. Unlike the United States, the European Union (EU) has signed the Kyoto Protocol, committing all of the member countries to national $\mathrm{CO}_{2}$ reduction. In Europe, the carbon market is separate from renewable energy markets, and renewable energy does not receive allowances for carbon under the Emission Trading Scheme. The rationale is that renewables emit no carbon, and, therefore, do not need allowances. In addition, there are other policies in effect supporting renewables including feed-in tariffs and quota obligation systems (similar to RPS). Renewables are also seen as benefiting from increased fossil generation costs. Some countries do use RECs to meet EU or individual country renewable energy targets, and for voluntary markets. At this time, there is no clear evidence that the carbon-trading market has had an adverse impact on the voluntary renewable energy market. However, it is not clear whether consumers understand that their purchases of renewable energy do not reduce emissions.

\section{Policy Options for Enabling Renewable Energy Claims}

On the assumption that the cap-and-trade approach to carbon regulation will expand, we discuss a number of policy options that would enable purchasers of renewable energy to affect emissions levels and make associated claims. Regardless of the policy option, and even without any policy supporting voluntary markets, it should be acknowledged that consumers can simply purchase and retire carbon emission allowances independent of a renewable energy purchase. In fact, consumers may increasingly do this if it is less expensive than achieving emission reductions with renewable energy purchases.

Set-aside Allocations to Renewable Generators. Allocating allowances to renewable energy generators is one way to credit renewable generation with the emissions benefits they provide under a cap-and-trade program. One approach for allocating allowances to renewables is to specify - or set aside - a certain percentage of total allowances to be granted to renewable energy generators. There is precedent for using set-asides for renewable energy and efficiency under the $\mathrm{SO}_{2}$ cap-and-trade program and the $\mathrm{NO}_{\mathrm{x}}$ budget trading program, and several states have proposed set-asides under the new Clean 
Air Interstate Rule (CAIR) trading program for $\mathrm{NO}_{\mathrm{x}}$. Some potential disadvantages of this approach are that the set-aside must be defined in advance and might not be big enough over time to accommodate all renewables, especially if the amount of renewable generation grows. In addition, renewable generators have to apply for the allowances rather than obtaining them automatically, which adds transaction costs and uncertainty as to whether allowances will actually be obtained. A renewable generator can convey an allowance with the sale of renewable energy or RECs, and the retirement of the allowance is a clear basis for making an emissions-reduction claim. However, there is no guarantee that allowances will remain bundled with RECs for sale in voluntary markets, as generators will seek to maximize revenues from all available markets, and may find it more profitable to sell an allowance to an emitter.

Output-based Allocations to Renewable Generators. Output-based allocation is another way to allocate allowances to renewables. With output-based allocations, allowances are granted to generators based on the quantity of electricity produced by each electric generator under the cap. Allocations are made proportionately to a generator's percentage of the total generation times the pool of allowances available for the allocation period. A renewable generator could, thus, earn its proportionate share of allowances and sell them to emitters who need them, or sell them for retirement with its RECs. There is some precedent for output-based allocation: The new CAIR rule includes a partial output-based allocation for new sources (fossil fuel only), and both Wisconsin and Pennsylvania have proposed a full output-based allocation, including to renewables, for their $\mathrm{NO}_{\mathrm{x}}$ trading programs under CAIR. Overall, output-based allocation has some advantages for renewables over a set-aside in that there are fewer transaction costs and the allocation of allowances is more reliable. As with a set-aside, retirement of the allowance would result in a clear reduction in emissions, although there is no guarantee of retirement, as generators could also sell allowances to emitting facilities.

Load-Based Cap. While load-based caps are being considered by several states, they have not yet been implemented. A load-based approach would place an emissions cap on the generation portfolio used to serve retail or end-use load, and would allocate allowances to the utilities or competitive electricity providers - generically, load-serving entities (LSEs) - as opposed to the generators. The LSEs would have to obtain enough allowances to cover the emissions of the portfolio of power plants from which they buy. If the cap is set low enough, LSEs would be motivated to acquire resources that have zero or low emissions. The detailed rules for implementing a load-based cap would determine whether emission benefits claims are possible with voluntary purchases. The load-based cap approach is untested and many details remain to be worked out to enable an emission-reduction claim.

Reduce the Cap to Account for Renewable Energy Demand. Another approach that would enable renewables to make GHG emissions benefits claims is if regulators consider demand for renewable electricity when setting the cap, or periodically reduce the cap to reflect growing demand for renewable electricity. Periodic reductions in the cap could be based on either projected demand or on actual demand after the fact. This approach could apply to renewable energy demand from state RPS policies as well as 
projected voluntary demand from retail consumers purchasing differentiated green power products. In this manner, renewable generators would not actually receive allowances, but they would reduce overall emissions because fewer allowances would be available in the allowance pool.

Retire Allowances on Behalf of Renewable Energy Sales. Another possible approach is for regulators to consider demand for renewable electricity and reduce the number of allowances allocated to emitters accordingly. This method focuses on retiring allowances after the cap is established. Similar to reducing the cap, this approach could apply to renewable energy demand from state RPS policies as well as projected voluntary demand from retail consumers purchasing differentiated green power products. Adjustments could be based on either projected demand or on actual demand after the fact. In this manner, renewable generators would not actually receive allowances, but they would reduce emissions because some emission allowances would never enter circulation and would be retired on their behalf. The final RGGI Model Rule was revised to allow for this approach for voluntary demand, but each participating state must affirmatively adopt the option. At the time of this writing, it is too early to know whether RGGI states will include this approach in their rules.

\section{Conclusion}

In an era of carbon regulation, voluntary renewable energy markets will continue to play an important role because many consumers may be interested in supporting renewable energy development beyond what is supported through mandates or other types of policy support. Some consumers may not be satisfied that emissions caps or other regulatory actions are sufficient to meet their environmental goals. In addition, businesses and organizations not subject to carbon regulation may be interested in taking action to reduce the impacts of their own emissions footprints. Businesses and consumers may also want to help support renewable energy today to help transform the technology to meet long-term emissions-reduction goals, or for the other benefits that renewable energy technologies provide, such as energy security, economic development, and fuel price stability.

Generally, the implementation of policies to control or reduce carbon emissions is likely to provide a market benefit to renewable energy sources by increasing the cost of production from carbon-emitting energy sources. However, voluntary renewable markets, in which purchases are often based on the ability to make environmental claims, could be negatively impacted unless these policies are properly structured.

Under carbon cap and trade, both the methods for setting the emissions cap and for allocating allowances are important for emission-reduction claims. Allocating allowances to renewable energy generators is one way to credit renewable generation with the emissions benefits they provide. A reduction in carbon emissions below the level of the cap can be achieved by retiring an allowance, ensuring that it is not sold to an emitter. A renewable energy marketer could convey an allowance with the sale of renewable energy or RECs, and the retirement of the allowance is a clear basis for making an emissions- 
reduction claim. However, there is no guarantee that the allowances will remain bundled with the RECs, as generators will seek to maximize revenues in all available markets. Other approaches, such as reducing the cap or automatically retiring allowances to account for current and future renewable energy generation would enable consumers to affect GHG emissions levels with their renewable energy purchases, but would not provide renewable energy generators the option of selling allowances in emissions markets. Thus, policy structures that are best suited for voluntary renewable energy markets are not necessarily the preferred policy options for renewable energy generators.

Voluntary renewable energy markets have been growing rapidly. If cap-and-trade policies are designed such that voluntary renewable energy purchases do not lead to overall carbon emission reductions, this will limit the GHG benefit claims of purchasers and pose a challenge for future renewable energy marketing. Going forward, federal and state energy and environmental decision makers need to be cognizant of the effects of carbon policy designs on voluntary renewable energy markets and work together to coordinate policies that will further both the desire to reduce carbon emissions and the ability of consumers to benefit from renewable energy purchases. 


\subsection{Introduction}

Voluntary markets for renewable energy, or "green power markets," provide an avenue for consumers to support the development of renewable energy sources by enabling them to choose cleaner electricity sources for their own energy consumption. This market is important in that it empowers consumers to affect the resources used to supply their own energy needs. While, initially, most green power products targeted residential consumers, recent growth in voluntary markets has been primarily fueled by large purchasers, including Fortune 500 companies and other businesses, universities, and government agencies.

As a result of increased interest among the nonresidential sector, voluntary markets are growing rapidly. In 2005, sales of renewable energy in voluntary markets increased nearly $40 \%$ following an increase of more than $60 \%$ during 2004 . At the end of 2005 , voluntary markets were supporting a capacity equivalent of about 2,000 MW of new renewable energy generation, which represents $22 \%$ of renewable energy capacity additions since 1997 when these markets began (Bird and Swezey 2006). Thus, voluntary markets help to support a significant fraction of new U.S. renewable energy-generating capacity.

While there are a number of benefits of renewable energy sources, many consumers have been motivated, at least in part, to purchase renewable energy because of its greenhouse gas (GHG) benefits. Currently, purchasing green power is an accessible and relatively easy and transparent way in which customers can reduce their carbon footprints. Most utilities and independent marketers that offer green power options promote their products by touting the GHG benefits and, in fact, some marketers actually sell carbon reductions derived from renewable energy generation to enable consumers to "offset" the carbon dioxide $\left(\mathrm{CO}_{2}\right)$ emissions associated with their electricity consumption, car and plane travel, and home heating energy use. Likewise, many purchasers point to the GHG benefits of their green power purchases in news releases and other promotional materials.

Emerging carbon regulation in the United States has the potential to substantially affect voluntary markets for renewable energy. Carbon regulation is now developing in the Northeast under the Regional Greenhouse Gas Initiative (RGGI, pronounced "Reggie") and in California as a result of recently adopted legislation (AB32). There is increasing discussion about carbon regulation at the national level as well. To achieve GHG reductions, both RGGI and California plan to implement cap-and-trade programs, which would enable emitters to trade allowances to meet emissions targets. There is precedent for using cap and trade to control emissions, such as the successful national sulfur dioxide $\left(\mathrm{SO}_{2}\right)$ cap-and-trade system developed under the Clean Air Act Amendments of 1990 to address acid rain.

In general, renewable energy does benefit from carbon cap-and-trade programs because compliance with the cap will increase the costs of fossil fuel generation, which will improve the cost-effectiveness of renewables. In addition, such programs may provide an 
incentive to capped entities to use renewable energy to meet future load growth without exceeding the cap. The stringency of the cap determines the level of incentive provided.

However, cap-and-trade programs can also impact the ability of renewable energy generation to affect overall $\mathrm{CO}_{2}$ emissions levels, depending on the design of the program. If renewable generation sources are not accounted for under the cap (through the retirement of allowances or in setting the level of the cap), then they will not affect the overall level of $\mathrm{CO}_{2}$ emissions, and purchasers of renewable energy have no basis for claiming overall emission reductions. Therefore, the implementation of carbon cap-andtrade programs has important implications for voluntary renewable energy markets.

These same issues also pertain to other types of cap-and-trade programs, such as those for $\mathrm{SO}_{2}$ and $\mathrm{NO}_{\mathrm{x}}$, but carbon cap-and-trade programs have more significant implications for renewable energy markets. This is true because renewable energy sources offer one of the few options for generating electricity without $\mathrm{CO}_{2}$ emissions, whereas emissions control technologies can be used to reduce $\mathrm{NO}_{\mathrm{x}}$ and $\mathrm{SO}_{2}$ emissions. And consumers may be more interested in achieving reductions in GHG emissions than emissions of specific air pollutants such as $\mathrm{NO}_{\mathrm{x}}$ and $\mathrm{SO}_{\mathrm{x}}$. Furthermore, carbon regulation is beginning to emerge, while emissions trading markets have already been established for $\mathrm{SO}_{2}$ and $\mathrm{NO}_{\mathrm{x}}$.

While carbon regulation may affect renewable energy development more broadly, this paper focuses primarily on the potential effects that emerging mandatory carbon markets will have on voluntary renewable energy markets. ${ }^{1}$ First, the paper examines the extent to which GHG benefits motivate consumers to make voluntary renewable energy purchases, and the claims that large commercial and institutional consumers currently make regarding their purchases. Next, the paper summarizes key issues emerging as a result of these overlapping markets, such as the implications for renewable energy marketing claims, the demand for and price of renewable energy certificates (RECs), and the use of RECs in multiple markets (disaggregation of attributes). Then, it describes carbon regulation programs under development in the Northeast and California, and how these might affect renewable energy markets in these regions, as well as the potential interaction between voluntary renewable energy markets and voluntary carbon markets, such as the Chicago Climate Exchange (CCX). The paper also briefly summarizes the experience in the European Union, where carbon is already regulated. Finally, the paper presents policy options for policymakers and regulators to consider in designing carbon policies to enable carbon markets and voluntary renewable energy markets to work together.

\footnotetext{
${ }^{1}$ The paper also includes limited discussion of impacts on renewable energy compliance markets
} 


\subsection{Relationship between Voluntary Renewable Energy Markets and Carbon}

\section{Climate Change as Motivator for Green Power Purchasers}

There are a number of reasons why consumers buy green power, including environmental benefits (air pollutant and GHG emissions), health benefits, fuel diversity, energy security, local economic development, encouraging the development of new technologies, resource protection for future generations, and energy price stability; and, for nonresidential consumers, public relations benefits. (Holt and Wiser 1999; Holt et al. 2001; Blank et al. 2002; Hanson 2005)

Residential consumers, in particular, purchase renewable energy for a variety of reasons, ${ }^{2}$ so it is difficult to discern the relative importance of GHG benefits as a motivator. However, most consumers believe that they are creating environmental benefits when they purchase green power and consider it to be an important benefit. While some marketers do not focus on environmental messaging for residential consumers, many have found that it is very important to do so.

For nonresidential customers there is clear evidence to suggest that GHG benefits are an important motivator. For example, nonresidential consumers are often interested in purchasing green power because it is a convenient tool for meeting their internal environmental goals or for taking credit for GHG reductions under a future regulatory regime and, thus, reducing future regulatory risks (Hanson 2005; Blank et al. 2002; Holt and Wiser 1999). These and other indicators are discussed in more detail below.

To illustrate the importance of the nonresidential voluntary market, purchases by businesses and institutions represented $65 \%$ of the 8.5 million MWh of renewable energy sold through voluntary markets during 2005 (Bird and Swezey 2006). And nonresidential purchasing has accelerated in recent years. For example, purchases by members of the U.S. Environmental Protection Agency (EPA) Green Power Partnership, which encourages organizations to purchase renewable energy as a way to reduce the risk of climate change and the environmental impacts associated with conventional electricity use, doubled during 2005. And growth has remained strong in 2006: As of September 2006, more than 600 organizations, including Fortune 500 companies; local, state, and federal governments; and colleges and universities voluntarily purchased more than 7 million MWh of renewable energy, up from 4 million MWh at the end of 2005 (Collison 2006; Amato 2005). Overall, participation among the nonresidential sector has led to substantial growth in U.S. voluntary markets, and, therefore, it is important to consider what motivates these consumers.

\footnotetext{
${ }^{2}$ A recent poll of residential customers sponsored by the U.S. Department of Energy found that consumers have a variety of reasons for purchasing or wanting to purchase renewable energy. Respondents indicated the following reasons: to improve today's environment (32\%), to leave our children and grandchildren a cleaner environment (30\%), to improve U.S. energy security (24\%), to support the development of new technology $(23 \%)$, to create local jobs and improve the economy $(21 \%)$, to protect against fuel price increases (20\%), all of these (58\%). (Opinion Research Corporation 2006.)
} 
Participation in GHG registries is evidence that companies and institutions are motivated to purchase renewable energy because of concerns over climate change. Under these programs, companies and organizations register to protect their early actions as a form of risk management. If carbon emissions are regulated in the future, registration with a credible and transparent reporting system will help credit these early actions toward compliance. In GHG registries, voluntary purchases of renewable energy are generally used to adjust the GHG emissions associated with a company's power purchases, which are considered indirect emissions (see Textbox for definition).

\section{GHG Accounting Definitions}

Under greenhouse gas registries, companies must report emission reductions under one of several categories: direct emissions, indirect emissions, and offsets (such as carbon sequestration).

Direct emissions (or Scope 1 Emissions) are defined as emissions from greenhouse gas sources that are owned or controlled by an organization. For example, emissions from electricity generation from an on-site system used to serve a portion of a company's electricity needs are considered direct emissions for that company. These are often referred to as Scope 1 emissions for the purposes of corporate GHG accounting.

Indirect emissions (or Scope 2 Emissions) are emissions that are a consequence of an organization's activities, but are not owned or controlled directly by the organization. For example, emissions from electricity purchased from a utility to serve a company's electricity needs are considered indirect emissions. Likewise, energy efficiency measures installed at the organization's facilities reduce indirect emissions for the organization. These are often referred to as Scope 2 emissions for the purposes of corporate GHG accounting.

Scope 3 Emissions are other types of indirect emissions resulting from business activities that a corporation may choose to include in its GHG inventory. The reporting of these emissions is generally optional. Examples include emissions associated with employee business travel, waste disposal, contractor-owned vehicles, production of purchased materials, product use, or outsourced activities.

Offsets. Definitions of offsets can vary considerably among GHG registries and programs. EIA defines offsets as emission reductions that are achieved through projects that generate verifiable emission reductions outside the scope of an organization's direct or indirect emissions. For example, under the federal Voluntary Reporting of Greenhouse Gases Program, companies report carbon sequestration projects that fix atmospheric carbon in a carbon sink through biological or physical processes, such as tree planting, forest preservation, modified forest management, and tillage practices that increase carbon storage on croplands.

WRI defines offsets as "discrete GHG reductions used to compensate for (i.e., offset) GHG emissions elsewhere, for example to meet a voluntary or mandatory GHG target or cap. Offsets are calculated relative to a baseline that represents a hypothetical scenario for what emissions would have been in the absence of the mitigation project that generates the offsets. To avoid double-counting, the reduction giving rise to the offset must occur at sources or sinks not included in the target or cap for which it is used."

Sources: EIA 2006 ; WRI 2004 
At the federal level, the U.S. Department of Energy manages the Voluntary Reporting of Greenhouse Gases Program, ${ }^{3}$ established by Section 1605(b) of the Energy Policy Act of 1992. Under the program, companies report their voluntary measures to reduce, avoid, or sequester GHG emissions. In 2004, the electric power sector accounted for $42 \%$ of the 226 organizations reporting to this registry, while others represented automotive products, metals, petroleum, chemicals, aerospace, pharmaceuticals, and electronic equipment industries (EIA 2006). Currently, purchasing renewable energy is one method of achieving emission reductions under the program, although the program is in the process of revising its rules. ${ }^{4}$

The California Climate Action Registry ${ }^{5}$ is perhaps the best known state effort to record voluntary actions to reduce GHG emissions. The 88 current members - not limited to organizations located in California - include cities, government agencies, municipal utilities, investor-owned utilities, electric power generation, educational institutions, health care, manufacturing, and financial services, among others. Under the registry, participating organizations can report their renewable energy or REC purchases under optional reporting procedures (California Climate Action Registry 2006).

In addition, the U.S. EPA runs a voluntary program called Climate Leaders ${ }^{6}$ through which partners set corporate-wide GHG reduction goals and inventory their emissions to measure progress. As of October 2006, more than 100 companies participated in the program, representing about $8 \%$ of total annual U.S. GHG emissions (U.S. EPA 2006). A number of participating companies purchase renewable energy to meet a portion of their GHG reduction goals.

Other evidence of the importance of climate change as a motivator is that many nonresidential green power purchasers point to the GHG benefits of their purchases in news releases, on their Web sites, or in other materials that describe their purchases (see Textbox). Some organizations discuss the need to address global warming in the context of their purchase. For example, according to the Aspen Skiing Company's president and CEO:

"The most pressing issue of our time is climate change, and addressing energy use is one of the most important actions we can take on that front." The company says further, "If everyone in the world bought renewable energy certificates like we have done, we'd be well on our way to solving the climate problem." (Aspen Skiing Company, 2006) http://www.aspensnowmass.com/environment/programs/Wind_Press_Release.pdf (accessed December 2, 2006)

\footnotetext{
${ }^{3}$ For additional information, see the Energy Information Administration's Web site at http://www.eia.doe.gov/oiaf/1605/frntvrgg.html, accessed October 23, 2006.

${ }^{4}$ The issue regarding the treatment of renewable energy and RECs has not yet been resolved under the revised reporting forms that are under development.

${ }^{5}$ For additional information, see http://www.climateregistry.org/Default.aspx?refreshed=true, accessed November 30, 2006.

${ }^{6}$ For additional information, see http://www.epa.gov/climateleaders/, accessed November 30, 2006.
} 
While other organizations may not issue such strong, clear statements, most large purchasers of green power mention the amount of GHG emissions that were prevented from entering the atmosphere as a result of the renewable energy that they are purchasing. The U.S. EPA provides a tool for companies to calculate the emissions benefits to help substantiate these claims. An excerpt from White Wave Food's Web site provides a typical example (see Textbox for additional examples):

"The amount of wind energy we're purchasing will prevent 16,000 tons of greenhouse gasses from entering our atmosphere. Our purchase has the same effect as eliminating the emissions of 3,200 cars, or planting more than 4,400 acres of trees.... Wind energy is clean. More wind energy means less smog, toxic pollution and greenhouse gas emissions.” http://www.whitewave.com/index.php?id=105 (accessed December 3, 2006) 


\section{GHG Claims by Organizations}

State of New Jersey: "As a testament to its commitment to promoting renewable energy generation, improving air quality, and reducing greenhouse gases, the state of New Jersey has emerged as the number one purchaser of green power (as a percentage of total load) among all state governments in the country... Benefits include...preventing an estimated 168,948 metric tons of $\mathrm{CO}_{2}$ emissions, which has helped the state achieve its goal of reducing its greenhouse gas emissions to 3.5 percent below 1990 levels by 2005."

http://www.state.nj.us/dep/dsr/bscit/GreenPower.pdf (accessed December 3, 2006)

HSBC Bank: "Recognizing the importance of climate change, last December, HSBC became the world's first major bank to commit to carbon neutrality and today its U.S. banking unit announced that it has offset a substantial quantity of its carbon emissions by purchasing 45,454 MWh of clean, wind energy certificates."

http://www.hsbcusa.com/ourcompany/pressroom/2005/news 042205 hsbc bank earth day.html (accessed December 18, 2006)

IBM: "The purchase of RECs demonstrates IBM's continued commitment to taking action on climate change and support for the development of renewable energy. IBM recognizes that global climate change is an important environmental and business issue. The company has taken voluntary actions to conserve its energy use and to reduce the emissions of greenhouse gases associated with its energy use and operations."

http://www.ibm.com/ibm/environment/news/rec 2005.shtml (accessed December 13, 2006)

Montgomery County (MD): "The wind energy purchase is a major step towards meeting the region's air quality goals for the reduction of greenhouse gas emissions that contribute to global climate change...The environmental benefits from this purchase are equivalent to a yearly reduction of: 42 million pounds of carbon dioxide, 95,000 pounds of nitrous oxides, and 1.4 pounds of mercury. The carbon dioxide reduction achieved is equivalent to 36 million miles not driven or 2.9 million trees planted."

http://www.montgomerycountymd.gov/Apps/News/press/Displaylnfo.cfm?ltemID=895 (accessed December 13, 2006)

Staples: "We are committed to reducing the effects of our energy use on climate through an integrated approach including conservation, the adoption of renewable energy technologies where financially viable and the purchase of certified renewable-energy certificates... Through the purchase of certified RECs from landfill gas and wind energy projects, we offset the environmental impacts of more than 53 megawatt-hours of conventional electricity with renewably generated electricity, resulting in a savings more than 46,000 metric tons of carbon dioxide equivalents $\left(\mathrm{mtCO}_{2} \mathrm{e}\right)$ in 2005 . Since 2001 , we have decreased our net GHG emissions per square foot across all properties by more than $22 \%$."

http://www.staples.com/sbd/img/content/soul/pdf/staples 2005 corporate responsibility report.pdf (accessed December 13, 2006) see p. 39

Johnson \& Johnson: "As indicated in our Next Generation Goals, adopted in 2000, it is the responsibility of each Company/Business Unit to meet our greenhouse gas reduction goal of $4 \%$ reduction by 2005 and a $7 \%$ reduction by 2010 , in absolute terms with 1990 as a base year. The pathways for a climate friendly energy policy include five elements: energy efficiency improvements in all of our operations; cogeneration; on-site renewable energy that produces no $\mathrm{CO}_{2}$ emissions; renewable electricity purchases; and carbon trading and sequestration." http://www.jnj.com/community/environment/policies/climate friendly.htm (accessed December 13, 2006)

The City of Bellingham, Washington: "The city's green power purchase represents the elimination of about 13,000 tons of carbon dioxide pollution... That's like not driving 22 million miles. It is pretty clear that this is the single biggest thing that we can do to help protect the climate. Protecting the climate needs to be our top priority, and this is a huge step in that direction." (City of Bellingham, 2006) http://www.cob.org/features/2006-07-31-green-power.htm (accessed December 18, 2006)

National Ski Area Association: "Ski resorts across the country are purchasing green power to offset their electrical energy use. As part of the industry's Keep Winter Cool program (www.keepwintercool.org) to combat global warming, the National Ski Areas Association (NSAA) has encouraged all of its members to buy green power.... The use of green power can help in the fight against global warming, help clean up the air and help decrease dependency on foreign energy sources." http://www.nsaa.org/nsaa/press/0607/061009-green-power.asp (accessed December 13, 2006) 


\section{Marketing Renewable Energy and Climate Change Benefits}

The importance of climate change as a motivator for green power purchases is also made evident by marketer claims. Most green power marketers and utility green power programs make prominent claims on their Web sites and marketing materials that consumers can reduce carbon levels with their green power purchases. This is one way of communicating the benefits of their products; however, some highlight these benefits more than others (see Textbox).

There are several business models for marketing renewable energy that, to varying degrees, connect purchases with GHG emission benefits. Increasingly, a number of marketers are positioning products as primarily providing carbon reduction benefits. We categorize some of the most common approaches to marketing renewable energy or carbon benefits associated with renewable energy below. Some marketers use a blend of these approaches.

- Traditional marketing of renewable energy or RECs. Currently, the most common approach to marketing renewable energy is to sell renewable electricity or RECs for a consumer's electricity use. Under this approach, the marketers make some claims about carbon emission reductions in marketing materials (see previous Textbox), but also describe other benefits of renewable energy, such as protecting resources for future generations, fuel diversity, economic development benefits, energy security, etc. Most utility green power programs fall under this category, as will most REC marketers, although some of these companies also use carbon emission calculators (described below).

- Carbon emissions calculators. A number of companies allow consumers to calculate the carbon emissions associated with their electricity consumption and sometimes other energy consumption, such as car and plane travel and home heating energy use, and purchase renewable energy or RECs equivalent to their total carbon emissions footprint. This marketing approach focuses explicitly on the GHG reduction benefits of green power by tying purchases directly to a consumer's carbon emissions. Carbon calculators are becoming increasingly common. Examples of this approach include online calculators operated by the Bonneville Environmental Foundation and 3 Phases Energy Services. $^{7}$

- Selling carbon "offsets." A growing number of organizations are now selling carbon emission reductions sourced from RECs, or a blend of RECs and other carbon reduction methods such as carbon sequestration or energy efficiency, to help consumers reduce their carbon footprints. ${ }^{8}$ Under these types of

\footnotetext{
${ }^{7}$ See online calculators at https://www.greentagsusa.org/GreenTags/calculator intro.cfm and http://www.3phases.com/certificates/calculator/calc.php, both accessed November 30, 2006.

${ }^{8}$ In fact, some carbon offset products do not rely on renewables, but these are not the focus of the discussion here.
} 
programs, consumers purchase "offsets" equivalent to the carbon emissions associated with their electricity use or other energy consumption, such as car and plane travel and home heating energy use. These offsets are retired on behalf of the purchasing customer.

While the term carbon "offset" generally has a specific meaning under carbon regulation programs, its meaning is the subject of debate in voluntary markets (Trexler and Kosloff 2006; Bristow 2006). Generally, however, REC-based carbon reduction products are sold under the premise that renewable energy is emissions-free and displaces fossil fuel generation, thereby offsetting $\mathrm{CO}_{2}$ emissions.

These products differ from conventional REC products in that consumers do not actually purchase RECs in $\mathrm{kWh}$ increments. Instead, purchases are made on a $\mathrm{CO}_{2}$ equivalent basis ( $\$$ ton $\mathrm{CO}_{2}$ ), and the money is used to purchase an equivalent amount of $\mathrm{CO}_{2}$ reductions through RECs and/or energy efficiency or reforestation projects. In some cases, expenditures through these kinds of programs are considered tax-deductible contributions. Examples of this approach include the Carbon Fund and Terra Pass. Also, Native Energy offers a similar product, but it differs in that it is sourced from the expected future output of new renewable energy projects.

Because voluntary carbon reduction products are becoming increasingly common, a number of organizations are developing certification programs or standards. For example, the Gold Standard ${ }^{9}$ recently launched a voluntary market standard for emission reductions, while the Climate Group and the International Emissions Trading Association have a standard under development (Bristow 2006). ${ }^{10}$ In addition, the Green-e program has released a proposed GHG product certification standard, which is designed to be an umbrella standard. ${ }^{11}$

\footnotetext{
${ }^{9}$ For additional information, see http://www.cdmgoldstandard.org/how does it work.php?id=44, accessed December 27, 2006.

${ }^{10}$ For additional information, see http://www.theclimategroup.org/assets/Voluntary_Carbon_Standard_Version_2 final.pdf, accessed January 8, 2006.

${ }^{11}$ For additional information, see http://www.resource-solutions.org/mv/ghgstandard.html, accessed December 27, 2006.
} 


\section{GHG Claims by Marketers and Providers}

Bonneville Environmental Foundation "Using clean renewable energy is friendly to the environment and reduces emissions of carbon dioxide and other greenhouse gases. Green Tags represent the real savings in carbon dioxide and other pollutants that occur when green power replaces burning fossil fuel." https://www.greentagsusa.org/GreenTags/index.cfm (accessed December 13, 2006)

Native Energy WindBuilders ${ }^{\text {sm }}$ is for people like you who are concerned about global warming and want to do something about it. WindBuilders ${ }^{\mathrm{sm}}$ is simple, and it gets results. You'll help build a new wind farm and keep global warming pollution out of the air. Keep your choice of 6, 8, or 12 tons of carbon dioxide out of the air, or use the SafeClimate Carbon Calculator provided by our friends at the World Resources Institute to calculate your own $\mathrm{CO}_{2}$ footprint. http://www.nativeenergy.com/services.html (accessed December 13, 2006)

TerraPass Although many of our projects have ancillary benefits in reducing other types of emissions, our focus as an organization is to reduce the pollution known to cause global warming. Therefore, our only claim is to reduce carbon dioxide equivalents as defined by the IPCC. http://www.terrapass.com/about/faq.html (accessed December 13, 2006)

Community Energy Wind energy is a clean and inexhaustible energy source. Each year one 215 -foot-tall wind turbine prevents the release of nearly 4 million pounds of $\mathrm{CO} 2$ which contribute to global warming. When compared to the average electric generation mix, the carbon dioxide benefit is equivalent to planting over 3,800 trees or taking 315 cars off the road each year! http://www.communityenergy.biz/adopt/adopt windmill.html (accessed December 13, 2006)

Sterling Planet What you pay for when you buy RECs is the benefit of displacing other nonrenewable sources from the regional or national electric grid.... To illustrate the environmental benefit, a customer purchasing 1,000 kilowatt hours (kWh) per month in the form of RECs annually offsets nearly 17,000 pounds of carbon dioxide emissions from conventional power plants. http://www.sterlingplanet.com/questions.php (accessed December 13, 2006)

CarbonFund Offsetting your carbon (or climate) footprint allows you to become part of the solution to climate change by supporting the reduction of carbon dioxide emissions equal to your carbon footprint. http://carbonfund.org/site/pages/why offset carbon/ (accessed December 13, 2006)

We Energies Our Energy for Tomorrow renewable energy program makes it easy for you to make a difference in the environment by increasing electricity production from energy sources such as wind, water, solar and landfill gas....A typical electric customer enrolled at 100 percent can reduce greenhouse gas emissions by 1,355 pounds.

http://www.we-energies.com/residential/acctoptions/eft.htm (accessed December 13, 2006)

Conservation Services Group For every unit of renewable energy generated, an equivalent amount of renewable certificates are produced. The purchase of these certificates helps offset conventional electricity generation in the regions where our renewable generation is located. The purchase provides global environmental benefits including reducing global climate change and regional air pollution.

http://www.climatesave.com/about.html (accessed December 13, 2006)

Portland General Electric Green Source, allows PGE to purchase pollution-free electricity through renewable energy sources such as wind and geothermal technologies on your behalf. Plus, an Oregon household (or business) can reduce its share of carbon dioxide $\left(\mathrm{CO}_{2}\right)$ emissions and offset as much as 8,400 pounds in one year - as much as a car would produce when driven more than 9,000 miles. http://www.portlandgeneral.com/renewables.asp?bhcp=1 (accessed December 13, 2006)

FPL - Sunshine Energy (solar) Choosing Sunshine Energy is one of the most important things you can do to reduce air pollution. In just one year as a Sunshine Energy customer, you can avoid over 8,000 pounds of carbon dioxide (CO2) emissions nationwide - as much as a car would produce in almost 9,000 miles of driving.

http://www.fpl.com/residential/electric/sunshine energy.shtml (accessed December 13, 2006) 


\section{What Kinds of Claims Can Be Made About GHG Benefits Currently?}

While marketers and purchasers of renewable energy are making a variety of claims today about the GHG benefits of renewable energy or RECs purchases, there is increasing debate about the legitimate scope of these claims.

The Environmental Marketing Guidelines for Electricity, developed by the National Association of Attorneys General (NAAG), provide guidance and general principles for marketers to follow to ensure that consumers are not misled by marketing tactics. Three relevant principles with respect to GHG benefits are deception, substantiation, and overstatement of environmental attributes. According to the NAAG guidelines (NAAG 1999):

2 (a) Deception - A claim is deceptive, and therefore unlawful, if it contains an express or implied representation or omission of fact that is likely, or has a tendency, to mislead consumers.

2 (b) Substantiation - Any party making an express or implied claim that presents an objective assertion about the environmental attributes of an electricity product or company must, at the time the claim is made, possess and rely upon a reasonable basis substantiating the claim. In substantiating technical claims about electricity products or companies, a reasonable basis consists of competent and reliable evidence which supports the claims made.

2 (e) Overstatement of Environmental Attributes - An environmental marketing claim should not be presented in a manner that overstates the environmental attribute or benefit, expressly or by implication.

The benefits that renewable energy sources or RECs provide stem from the fact that renewable energy sources are emissions-free or have low GHG emissions. Renewable energy sources create an emission benefit by displacing emissions from either existing or new fossil fuel generation sources that would otherwise have been used to generate electricity.

There appears to be general consensus in the industry that a purchaser of renewable energy or RECs can make claims regarding the improved GHG emissions profile of their power purchases. Likewise, marketers can make corresponding claims to prospective purchasers. In a recent report, WRI has provided guidance on how companies can calculate and account for the GHG emissions benefits associated with REC or renewable energy purchases (Putt Del Pino 2006). Typically, in GHG accounting systems, companies and institutions record the GHG emissions associated with their power purchases as indirect emissions (Scope 2), and generally the GHG emissions benefits of a renewable energy or REC purchase can be accounted for as an adjustment to these indirect emissions (WRI 2004; Putt Del Pino 2006), although treatment can be by registry. 
There is considerable debate, however, about using renewable energy or RECs to substantiate broader claims of offsetting GHG emissions associated with other emitting activities, such as natural gas consumption, employee airplane travel, or automotive emissions. Currently, there is no industry consensus with respect to these kinds of claims.

The debate is largely about what types of projects can qualify as credible "offsets"-or GHG reductions that are used to compensate for (i.e., offset) other types of emissions (see Textbox for definitions). Under GHG accounting, renewable energy or RECs may need to qualify as offsets to be used to offset emissions other than power purchases. Part of the problem is that, in the absence of national carbon policy, there is no widely accepted definition of what constitutes an "offset" in voluntary markets, although a number of organizations are developing standards.

Most existing standards for offsets specify that offsets must result in emission reductions that are real, additional, verifiable, enforceable, and permanent. ${ }^{12}$ One hurdle that can be difficult for renewable energy projects to meet is whether the project is "additional" to what would have otherwise occurred. There are two types of tests for whether GHG reductions are additional: whether the reductions are additional to what would have happened 1) without the project, and 2) without the payment promised in an offset transaction (Broekhoff 2007). The second issue, in particular, is difficult for renewables because most renewable energy projects are not built for a single purpose. One possible approach to addressing concerns over additionality is to ensure that individual MWh from a renewable facility are used for only a single purpose, such as compliance with a state RPS, voluntary markets, or a carbon offset. This is the approach taken by CCX and the current approach to eliminating double-counting in voluntary green power markets.

Another challenge for renewables is that they displace emissions from fossil fuel generation and, thus, the emission reductions occur at a source controlled by someone other than the parties to the renewable energy project. Therefore, the ownership of the reduction is uncertain and could lead to double-counting in a GHG framework (i.e., the reduction could theoretically be claimed by the fossil plant as well as the renewable plant) (WRI 2004). However, if renewable energy generation displaces the need for a new power plant, there would be no double claim. Some industry stakeholders further argue that fossil generators are not making claims regarding emission reductions, except perhaps in programs such as the Chicago Climate Exchange (CCX) where they establish voluntary, but binding, emission-reduction targets. The Green-e program currently does not certify the output of facilities whose owners participate in CCX or other statesanctioned programs to avoid double-counting (Lieberman 2007).

\footnotetext{
${ }^{12}$ In a recent solicitation for $\mathrm{CO}_{2}$ offsets, the Climate Trust specified that purchased offsets must meet the following requirements: 1) Additional, meaning offset funding must be essential for the implementation of the project, i.e., proof is required that the mitigation measures would not occur in the absence of offset project funding. 2) Regulatory surplus, meaning the emissions benefit is over and above what is required by law, regulations, or other obligations. 3) Quantifiable, meaning the amount of carbon dioxide offsets can be measured, monitored, and evaluated. 4) Future, meaning the project will be implemented subsequent to contract execution (The Climate Trust 2005).
} 
Another perspective is that the important thing to consider is that a zero-emitting renewable energy facility creates an overall GHG emission benefit that could be used to offset emissions associated with a variety of emitting activities. This perspective focuses on the fact that renewables provide an emission reduction compared to fossil fuel generation, and this benefit could be applied to other types of emissions such as emissions from airline or car travel. A number of organizations currently market products based on this rationale, as discussed earlier.

Because of the current lack of clarity with respect to these issues, it would be useful for green power and GHG certification programs, government programs that encourage voluntary green power purchases, and perhaps the Attorneys General or Federal Trade Commission to provide guidance on the range of acceptable claims and the use of renewables as offsets. Going forward, as carbon regulations take effect, there will be an additional layer of complexity in the marketplace that may have implications for future claims. 


\subsection{Impact of Carbon Regulation on Renewable Energy Markets}

In the United States, carbon regulation is beginning to take form as a number of states have initiated their own policies and programs, and Congress is debating appropriate action at the federal level. ${ }^{13}$ Several states are also proposing to regulate carbon emissions through cap-and-trade programs. While there are other measures under discussion for limiting $\mathrm{CO}_{2}$ (e.g., a carbon tax), this report focuses on cap and trade as it appears to have the most momentum on the state and federal level, and it is the measure that has the most significant implications for voluntary renewable energy markets.

Interest in cap and trade is a result of the successful implementation of emission cap-andtrade regulation of $\mathrm{SO}_{2}$ under the Clean Air Act Amendments of 1990 and the experience under the federal $\mathrm{NO}_{\mathrm{x}}$ budget program. There is also precedent for using cap and trade in the European Union as a means to meet its GHG reduction obligations under the Kyoto Protocol. Cap-and-trade systems aim to create reductions at the lowest possible cost by enlisting market forces to determine the cheapest means to achieve the cap.

Before delving into the details and implications of emerging state cap-and-trade programs, we focus here on the issues that generally arise for renewable energy markets as a result of cap-and-trade programs. For example, if carbon is regulated under a capand-trade program, the claims that can be made by renewable energy generators or marketers with respect to carbon-reduction benefits could be affected. Depending on the policy design, this could have implications for the price of RECs and for demand for renewable energy in voluntary markets. Regulation also raises some policy interaction questions for RPS markets. This chapter explores these issues in turn. Chapter 4 describes emerging state carbon cap-and-trade programs and their potential impacts in more detail.

\section{Effect of Cap and Trade on Marketing Claims}

\section{Achieving Carbon Reductions under Cap-and-Trade Systems}

Under a traditional cap-and-trade system, the cap is set at a fixed level to achieve the desired reduction in emissions from a baseline year (e.g., 10\% reduction in emissions from 1990 levels by 2020). Cap-and-trade programs often are designed to achieve greater reductions over time, so the cap may be lowered in subsequent years to enable market participants to gradually achieve emission reductions. To achieve compliance with the capped emission level, market participants are allocated allowances to emit ( 1 ton per allowance), with the total number of allowances summing to the level of the cap. Market participants can purchase allowances from other participants to cover excess emissions, or sell allowances if they reduce emissions below their allocation.

\footnotetext{
${ }^{13}$ For example, at the federal level, senators John McCain, Jim Jeffords, Jeff Bingaman, and Dianne Feinstein have all offered proposals for carbon cap-and-trade programs. These have varied in the details, including the level of cap, baseline year vs. intensity, allocation approaches, and what entities would be capped.
} 
Under this type of system, a reduction in carbon emissions below the level of the cap can be achieved by retiring an allowance, ensuring that it is not sold to an emitter. Therefore, in order for renewable energy generators to be able to affect emissions levels, they will have to retire allowances that are allocated to them, purchase and retire them, or have allowances retired on their behalf by program administrators. Renewable energy sources could also claim to reduce emissions levels if current and future renewable energy generation is considered when setting the level of the cap.

To illustrate, if a new wind energy facility generates electricity at a time that causes a fossil fuel facility to back down, the emitting fossil fuel facility will generate less electricity and consequently emit less $\mathrm{CO}_{2}$. This creates excess allowances for the fossil fuel facility, which can then be sold in the open market, allowing other facilities to avoid controlling emissions and emit more $\mathrm{CO}_{2}$, bringing total emissions back up to the level of the cap.

If the wind generation facility offsets the need for a new fossil fuel plant, then existing emitters will not need to control emissions for the zero-emitting wind plant to come online. Figures 1 and 2 illustrate this point by showing the need for existing facilities to reduce emissions to enable a new natural gas plant to come online, while a new zeroemitting wind plant can come online without causing existing plants to reduce their emissions (Harmon and Hirschorn 2006; Jacobson 2007). In fact, the result of the new wind plant is that there will be less competition among existing emitters for allowances, and the price of allowances will be lower than it would if the new fossil-fuel facility had come online. Because new renewable energy generation will reduce the cost for emitting facilities to meet the cap, it may be more politically feasible to lower the cap in the future, but any such future emission reductions are uncertain.

In either case, i.e., whether the renewable energy plant displaces an existing or new fossil plant, the result is the same - the renewable energy facility does not reduce the overall level of carbon emissions.

Another way renewable energy can affect carbon emissions levels is if future renewable energy development is taken into account in setting the level of the cap (i.e., the cap is set lower to account for current or expected zero- or low-emitting renewable energy generation). Under this approach, it can be claimed that the renewable energy or RECs reduce emissions levels, because the cap is set at a lower level to account for the zero- or low-emitting renewable energy facilities. However, under this approach, the renewable energy generators would not have an allowance to sell in emissions markets. 


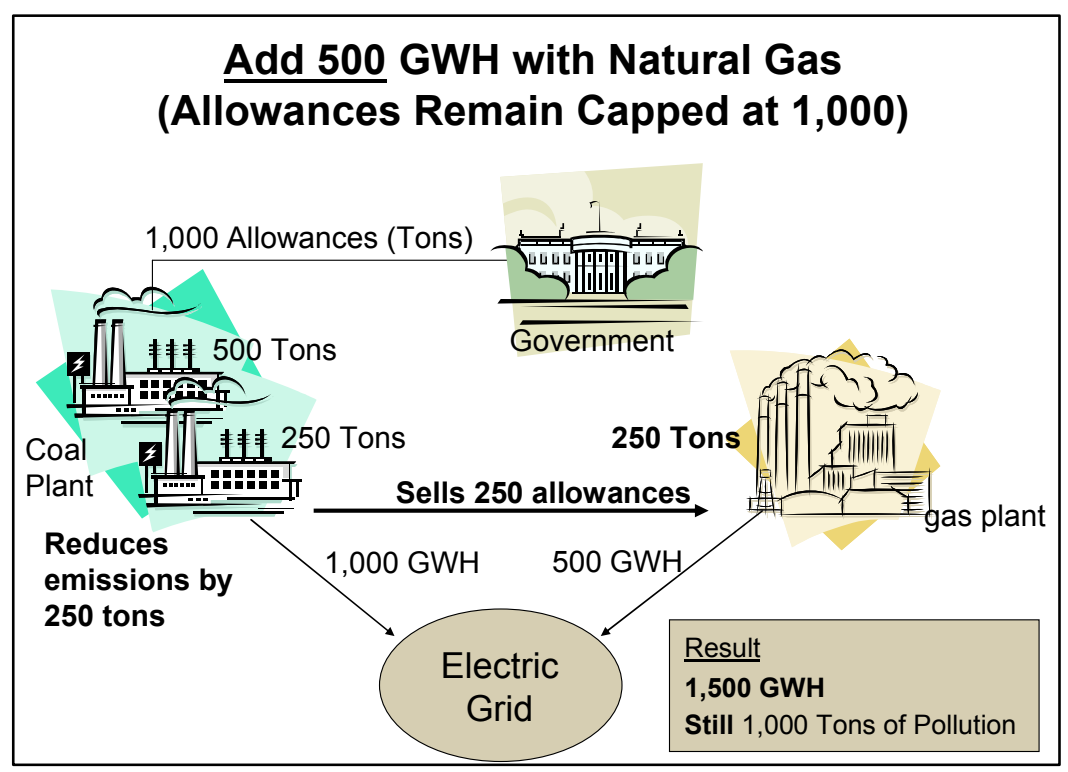

Source: Harmon and Hirschorn 2006

Figure 1: Emissions Impacts of Adding New Natural Gas Plant under Cap and Trade

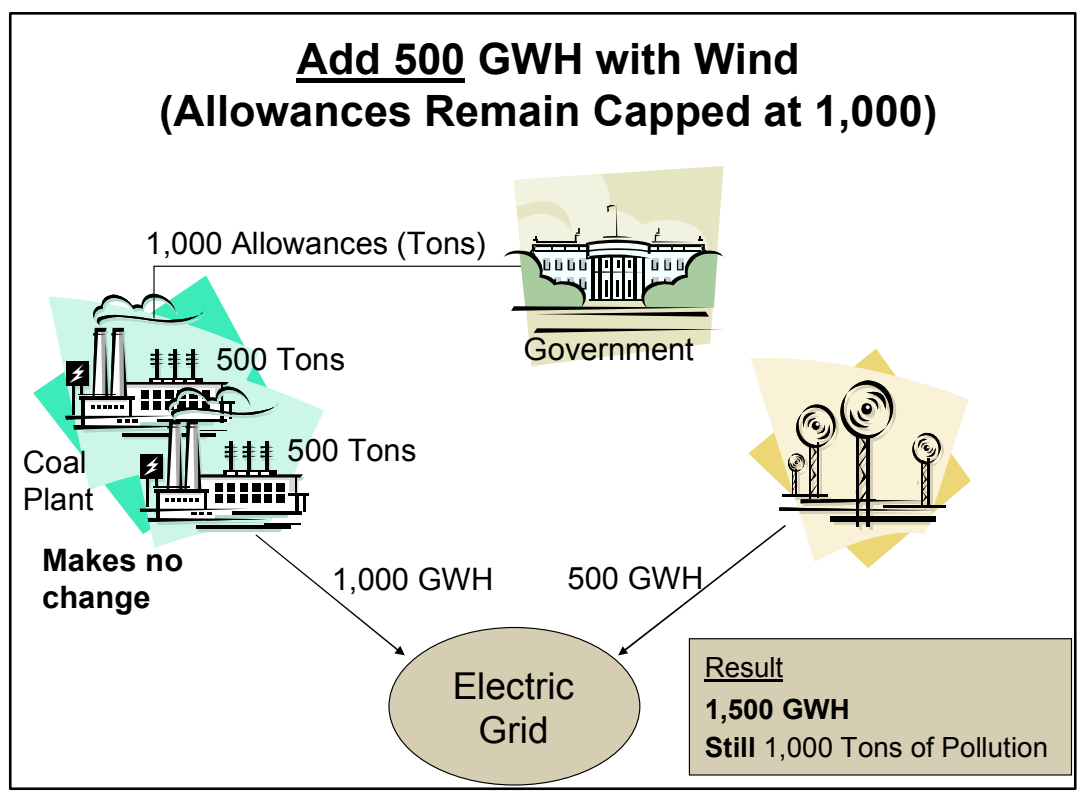

Source: Harmon and Hirschorn 2006

Figure 2: Emissions Impacts of Adding New Wind Facility under Cap and Trade 


\section{Allocating Allowances to Renewables}

Traditionally, emissions allowances have been allocated only to emitting power plants, i.e., those that burn fossil fuels, based on historic emissions or on the heat content of the fuels burned. For example, in the $\mathrm{SO}_{2}$ acid rain program, emission allowances were allocated to fossil power plants with a few minor exceptions (Wooley and Morss 2001). Other possible approaches are to allocate allowances in proportion to a generator's share (output-based) or supplier's share (load-based) of the overall electricity market, regardless of how the electricity is generated, or to auction some or all of the allowances to the highest bidders.

The primary argument for excluding renewables from receiving allowances or reducing the cap is that the emissions cap adds cost to the emitting plants, thereby making renewables and other nonemitting plants relatively more cost-competitive. In addition, focusing only on emitters reduces administrative complexity and costs.

Renewables advocates argue that without allocation of allowances to renewable generators, renewables will be excluded as a strategy for reducing emissions beyond those required by the cap. Because carbon caps may not be set at levels that are necessary to address the impacts of global climate change, consumers may want the option to voluntarily reduce emissions below the level of the cap. And a loose cap may provide little incentive for renewables. Renewable energy developers also argue that they should reap financial benefit from the emissions benefits that they provide, although this would not necessarily result in a reduction in emissions, if generators sell allowances to emitters. Specifically, renewable energy advocates have argued that: ${ }^{14}$

- Society needs all commercially viable options for making emission reductions.

- Renewable generators are emission-free and want to participate in emissions-trading programs.

- Inclusion in emission trading programs will allow renewable energy sellers to "own" the environmental benefit of their sources, and this environmental benefit will have value to investors, buyers, and other stakeholders. Enabling renewables to retain this value may be particularly important in the case of a loose carbon cap, which does little to improve the competitive position of renewables.

- Renewable energy will help society achieve its emission-reduction goals by expanding the green power market and achieving emission reductions beyond those required by regulation.

There is policy precedent in the United States for providing allowances to renewable energy sources, typically through renewable energy set-asides. For example, a small portion of allowances were set aside under the Clean Air Act Title IV SO $\mathrm{S}_{2}$ trading program for energy conservation and renewables, although few allowances were awarded because of restrictions on eligible entities and how they were awarded (Wooley and Morss 2001).

\footnotetext{
${ }^{14}$ Renewable Energy Working Group Steering Committee, “Approaches to Integrating Renewable Energy into Greenhouse Gas Trading Programs," submitted by the Center for Resource Solutions to the Regional Greenhouse Gas Initiative, June 2004. http://www.rggi.org/stakeholder comments.htm.
} 
In addition, seven states implemented renewable energy set-asides under the federal $\mathrm{NO}_{\mathrm{x}}$ Budget Trading Program (U.S. EPA 2005). Several other states have proposed renewable energy set-asides under the new Clean Air Interstate Rule, and at least two states (Wisconsin and Pennsylvania) have proposed an output-based allocation that would include renewable energy sources (Salerno 2006). Chapter 5 provides additional detail on allocation options and experience to date.

\section{Effect on Marketing Claims}

If renewable energy marketers receive and retire carbon emission allowances, then, by definition, the generation and use of renewable energy should result in real emission reductions and strengthen environmental marketing claims. But if renewables do not result in retired allowances or lower emissions caps, then environmental claims for renewable energy become problematic.

What benefits can marketers (or purchasers) claim if they do not retire an allowance or if the cap is not adjusted for renewable energy demand? If renewable energy does not result in a direct carbon reduction, the simplest claim that generators or marketers might make is that the renewable energy is "emission-free" or "pollution-free." This is the general approach to marketing renewable energy in Europe, because carbon and REC markets operate independently. However, under the NAAG Guidelines, claims that an energy product is "emission-free" or "pollution-free" might imply to consumers that by purchasing such energy, they are helping to reduce emissions.

Some stakeholders have suggested that a company that buys renewable energy might claim that it is reducing its own emissions profile because it would lower its indirect emissions (i.e., emissions that are outside of its direct control, such as power purchases) even though overall system-wide emissions of carbon would not be reduced. ${ }^{15}$ In this case, a marketer might make a claim that a purchase would offset "your emissions footprint." However, companies may resist the idea of making such claims, because overall carbon levels would be unaffected.

Some renewable energy advocates argue that even if allowances are not granted to renewables, they will provide environmental benefits in the long run. For example, if a significant amount of new renewable energy generation is added to the grid, the added zero-emitting generation may make it more cost-effective and politically feasible to reduce the level of the cap in future years (although, in the short term, it would simply make it easier and less expensive for fossil generators to comply with the cap). This view of long-run benefits, based on a common-sense argument, may justify making claims, but such claims are weaker and more difficult to substantiate than if allowances were allocated directly to renewable generators. Further, this may not prove sufficiently compelling to entice consumers to purchase renewable energy and could translate into weakness in the voluntary market.

\footnotetext{
${ }^{15}$ Conversation with Craig Hanson, World Resources Institute, October 2006.
} 
Other industry stakeholders argue that if a buyer of renewable energy really wants to make a carbon reduction claim, the market will respond and provide products that meet this need. For example, marketers might purchase an allowance and bundle it with a REC (some call this a "REC-plus" product), or the REC buyer might simply buy an emission allowance separately. However, this approach would likely increase the price for end-use consumers, thereby suppressing demand, or reduce the amount of revenue that goes to the renewable energy generator (see additional discussion below).

If marketers cannot make clear claims of environmental benefits as a result of carbon regulation, this may pose a significant challenge for marketing renewable energy to voluntary purchasers. The lack of GHG emissions from renewable energy sources are generally considered to be the most significant environmental benefit of these technologies. If marketers are restricted from making claims about GHG benefits, they may find it difficult to explain the benefits of an already intangible product to consumers. And it could reduce the motivation for nonresidential consumers, in particular, which could, in turn, stifle voluntary purchases of renewable energy.

\section{Effect on Price and Demand for Renewable Energy in Voluntary Markets}

Before discussing the influence of carbon markets on the price of RECs, it is helpful to review current market prices for both carbon and RECs, and the factors affecting prices today. During 2006, carbon traded on the Chicago Climate Exchange (CCX) at prices ranging from about $\$ 2$ to $\$ 4.50$ per metric ton $(\mathrm{MT})$ of $\mathrm{CO}_{2}$.equivalent. ${ }^{16}$ Prices in this market have remained relatively low, because it is a small voluntary market. In comparison, in the European Union where carbon is regulated, prices have been as much as an order of magnitude higher, ranging from $\$ 8 / \mathrm{MT}$ to $\$ 40 / \mathrm{MT}$ of $\mathrm{CO}_{2}$ equivalent. $^{17}$ U.S. carbon prices are widely expected to be higher in a regulated market environment than the voluntary CCX, but, of course, the stringency of the regulation will determine prices.

RECs sold in large-volume transactions in voluntary markets in the United States have ranged from $\$ 1 / \mathrm{MWh}$ to $\$ 5 / \mathrm{MWh}$ in 2006 , except for solar, which has reached $\$ 25 / \mathrm{MWh}$ or more. Table 1 presents voluntary market REC prices by resource type and location, with prices converted to $\$ / \mathrm{CO}_{2}$ displaced, using regional average $\mathrm{CO}_{2}$ emissions rates. On this basis, REC prices range from $\$ 2 / \mathrm{MT}$ to $\$ 14 / \mathrm{MT}$ of $\mathrm{CO}_{2}$ displaced. In voluntary markets, REC prices are determined by consumer willingness to pay for renewables, competitiveness of renewable energy generation, perceived quality of the product offered, and other factors such as RPS market demand.

\footnotetext{
${ }^{16}$ Data obtained from CCX http://www.chicagoclimatex.com/trading/stats/monthly/index.htm, accessed December 17, 2006.

${ }^{17}$ Data for 2006 from the European Climate Exchange http://www.ecxeurope.com/index flash.php for 2006. Prices converted to U.S. dollars assuming an exchange rate of $1.30978 \mathrm{USD} /$ Euro (December 17, 2006). Prices on the EUETS peaked on April 19, 2006, and then crashed in late April as countries began reporting a surplus in allowances (e.g., France, Sweden, and the Czech Republic). For additional information, see "Emissions Prices Drop to 13-Month Low After Sweden Shows Surplus," May 2, 2006 http://www.ecxeurope.com/pages/page553.php.
} 
Table 1: Voluntary Market REC Prices (New Renewables), 2006

\begin{tabular}{|l|l|l|l|l|l|l|l|}
\hline Resource & \multicolumn{2}{|l|}{ Wind } & Solar & Biomass & Geothermal & LFG \\
\hline Region & SPP & WECC/CA & National & CA & National & WECC/CA & SERC \\
\hline \$/MWh & $1.30-4.50$ & $3.00-5.00$ & $1.80-5.00$ & $21-25$ & $1.00-1.10$ & $1.80-4.00$ & 1.50 \\
\hline \$/MT $\mathbf{C O}_{2} \mathbf{e}$ & $1.50-5.00$ & $8.20-13.70$ & $2.80-7.90$ & $57-68$ & $1.60-1.80$ & $4.80-10.90$ & 2.40 \\
\hline
\end{tabular}

Source: Evolution Markets

Prices converted to $\$ /$ metric ton assuming average regional $\mathrm{CO}_{2}$ emissions rate from Egrid (U.S. EPA 2004).

\section{Impact of Voluntary Carbon Markets on REC Prices}

To date, CCX and other voluntary carbon markets have played little, if any, role in influencing REC prices, because the two markets have essentially operated independently. Under the CCX, carbon offsets have been derived primarily from efficiency and sequestration. While renewables are eligible to provide offsets under CCX, they have played a very small role in the CCX market to date, because prices have generally been higher in REC markets.

Outside of CCX, the recent emergence and rapid growth in voluntary "carbon offset" products sourced from other carbon reduction measures such as sequestration or energy efficiency are creating competition for voluntary market REC products. These products are generally sold in direct competition to REC products to consumers who wish to reduce their overall $\mathrm{CO}_{2}$ emissions levels. While consumers will likely benefit from greater competition and a wider variety of options, the growth in availability of these alternative carbon reduction products will likely put downward pressure on REC prices as they gain market share.

\section{Impact of Carbon Regulation on REC Prices and Demand}

With the introduction of carbon regulation, REC markets will gain an additional layer of complexity, affecting supply and demand. The form of carbon regulations will determine the magnitude of the impacts on REC markets. If carbon is regulated under cap and trade in a manner that renewables cannot make clear emission-reductions claims, this will likely reduce voluntary demand for renewable energy and put downward pressure on the price of RECs. Furthermore, if RECs no longer convey GHG benefits, their value will be diminished.

As mentioned earlier, consumers interested in achieving carbon reductions through their green power purchases would need to purchase and retire carbon allowances in conjunction with the REC. This would add cost to the product (REC plus carbon allowance), likely increasing the price to the end-use consumer, which would suppress demand, or lowering the value of the REC. Alternatively, buyers just after the carbon claim might simply buy allowances, retire them, and not bother buying renewable energy or RECs, again lowering demand. 
An important consequence of falling demand and lower prices for RECs is that renewable generators would receive less revenue. This would weaken the financial projections of project developers when they seek financing and could reduce investment in new renewable energy projects. A number of renewable energy developers have pointed to the benefit of having multiple markets for their output to reduce risks in undertaking projects. Financiers have only recently begun to value RECs as a source of project revenues, and some discount RECs markets as a source of stable, long-term revenues; therefore, any further weakening of these markets could reduce their ability to support new project development.

Another implication for REC markets is that it is conceivable that under future carbon regulation, carbon allowance prices could exceed voluntary market REC prices, reversing the current value relationship. In this case, any product conveying both an allowance and a REC would be more expensive than under current market conditions. This would be true if the renewable energy generators were to receive allowances or if allowances were purchased separately from the REC (REC-plus product). In the case in which generators received carbon allowances that they could sell in the emission market, they would be unwilling to sell the allowance bundled with a REC for less than they could receive in the two markets separately. This would lead to an increase in prices for products conveying emissions benefits, which would suppress voluntary market demand. Under high allowance prices, generators would have greater incentive to sell allowances in emissions markets, separate from the RECs, which could lead to a devaluation in RECs prices, but generators would be compensated by revenues from carbon allowances.

Taking a broader market perspective, renewables generally will benefit from carbon regulation because it will increase prices for fossil generators and, thus, improve the costeffectiveness of renewable energy generation. The level of the cap will determine the incentive provided for renewables; a tight cap will provide a strong incentive, while a loose cap may provide little incentive. A tight carbon cap will also likely encourage more direct investment by utilities in renewable energy projects, particularly over time as demand for electricity grows. Under a loose cap, the near-term response may be dominated by efficiency improvements at fossil fuel plants.

While renewables will reap benefits from carbon regulation, the role of voluntary markets is typically to support investment in renewables beyond what is supported through mandates or other types of policy support. Carbon caps may be insufficient to address the threat of climate change; therefore, additional action may be necessary to avoid potential impacts. If the viability or credibility of voluntary renewable energy markets is diminished, one avenue for consumers to affect change above and beyond regulatory measures will be lost. Although renewables are one possible long-term strategy for addressing climate change, declines in voluntary markets or their ability to stimulate new renewable energy development could limit near-term investments in renewable energy technologies that are important for improving the technology as a longer-term solution. Renewable energy sources may also warrant support in addition to that provided by carbon policy, because they provide other societal benefits, such as energy security, energy independence, lack of resource depletion, and air quality benefits. 


\section{Effect on Compliance REC Markets}

While the primary focus of this paper is on the effects of carbon regulation on voluntary renewable markets, carbon regulation also has important implications for renewable energy compliance markets, which we discuss briefly here. With the development of carbon markets, states will need to determine whether RECs used for RPS compliance must include (and retire) carbon allowances if allowances are granted to renewables. States will need to consider the objective of the RPS in making this decision. If the objective of the RPS is to achieve emission reductions, this can be achieved by retiring allowances with the REC or considering the RPS in setting the level of the carbon emissions cap.

A number of states articulate their policy objectives in RPS legislation or rules. Most policies mention expected environmental benefits, and about half are explicit in enumerating emission reductions among the expected benefits. For example, Colorado and Maryland are two states with a general expression of benefits, while California and Rhode Island have more specific expectations.

Colorado's RPS law, enacted by a vote of the people, reads, in part "to improve the natural environment of the state"; and Maryland's law states the RPS is adopted to provide, again, in part, "long-term decreased emissions, a healthier environment." California's legislation states that "The development of renewable energy resources may ameliorate air quality problems throughout the state and improve public health by reducing the burning of fossil fuels and the associated environmental impacts." The Rhode Island State Legislature adopted its RPS in expectation that "Increased use of renewable energy can reduce air pollution, including carbon dioxide emissions that adversely affect public health and contribute to global warming." If renewable energy generation does not lead to a retirement or reduction in emission allowances, these expectations will not be met (Holt and Wiser 2007).

Some states are explicit about whether allowances must be retired with a REC used for RPS compliance; and, as might be expected, states have taken different positions (Holt and Wiser 2007). New York and Colorado expect that emissions benefits and allowances, if any, must be retired for RPS compliance. Arizona's rules also take this approach, stating, "If an Affected Utility acquires, trades, or sells environmental pollution reduction credits or any other environmental attributes associated with an Eligible Renewable Energy Resource, the Affected Utility may not apply Renewable Energy Credits derived from that resource to satisfy the requirements of these rules."(ACC 2006)

On the other hand, Delaware and Pennsylvania (proposed rules) state explicitly that they do not require emissions benefits or allowances to be retired with the REC. A number of other states define a compliance REC as including all renewable and environmental attributes, but it is not clear what that could mean with respect to emission allowances. 
Allowing a REC to be used for compliance without emissions allowances would likely make it less expensive for entities to comply with the RPS and carbon policies, which would ultimately translate to savings for end-use consumers. Some developers and other industry participants advocate for this approach, because it would provide multiple revenue streams for project developers, if renewables are allocated allowances. However, it would mean that RPS policies would not affect overall carbon emission levels.

If states require emissions allowances to be retired with the REC for RPS compliance, they will ensure that the RPS results in emission reductions. This would make compliance more expensive, but would enable states to achieve their RPS objectives of cleaner air and GHG emission reductions. States could also achieve these RPS objectives by setting the emissions cap to account for expected RPS demand for nonemitting generation.

Finally, even if states decide to require any allowances allocated to renewables with the REC for RPS compliance, they may still count the allowances retired for RPS compliance toward their carbon reduction goal. California, for example, requires RECs used for RPS compliance to include any available emissions allowances, but plans to count the RPS carbon benefits toward the state's carbon goal (Wiser 2007).

\section{Effect of Receiving Allowances but Selling Them Separately from the REC}

If renewables receive allowances under cap-and-trade rules, there is no guarantee that they will remain bundled with the REC. Renewable generators may find it advantageous to sell the allowance separately from the REC if the two revenue streams combined provide more income than selling RECs bundled with allowances. If the introduction of carbon regulation increases the value of carbon allowances over those seen so far in voluntary carbon markets, reversing the current value relationship, renewable generators would have an even stronger motivation to sell the allowance separate from the REC.

Generators argue that the ability to participate in multiple markets would strengthen the financial viability of renewable energy projects and should lead to greater investment in new renewables. However, other industry participants argue that the expectation of additive revenue streams is illusory, as the value of RECs would drop if carbon benefits are stripped out.

Other stakeholders argue that any allowances granted to renewables should be included (and retired) with the REC to create maximum environmental benefit. This would ensure that the environmental benefits of voluntary purchases would be in addition to the environmental benefits of emission cap-and-trade programs. For example, the Green-e product certification program requires that retail REC products include any emissions allowances granted to renewables to be eligible for certification. ${ }^{18}$ In addition, the U.S. EPA's Green Power Partnership requirements state that: "for a purchase to qualify for the

\footnotetext{
${ }^{18}$ See the Green-e National Standard http://www.green-e.org/getcert_re_stan.shtml
} 
Partnership, Partners must ensure the green power or RECs they purchase convey the right to make all associated environmental benefit statements." 19

In essence, while most renewable energy stakeholders want to see renewable generators recognized for their emissions benefits, they share this objective for different reasonssome for enhancing revenues and supporting new projects, and others for achieving immediate environmental benefits and protecting consumers.

From a voluntary market perspective, the effect on marketing claims of selling emission allowances separately from the renewable energy or REC is the same as if renewable energy did not receive allowances at all. That is, neither the seller nor the buyer of renewable energy could claim a carbon reduction if the allowance has been sold to a third party. This returns us to the same question of motivation to buy renewable energy on the voluntary market.

\footnotetext{
${ }^{19}$ See Green Power Partnership Program Requirements Document http://www.epa.gov/greenpower/pdf/gpp_partnership_reqs.pdf.
} 


\subsection{Emerging Carbon Markets in the United States}

This chapter describes several emerging carbon-trading systems and how the design of these programs may affect voluntary renewable energy markets. First, we discuss several U.S. carbon-trading programs including the Regional Greenhouse Gas Initiative (RGGI) in the Northeast; California's GHG reduction programs, which will likely include trading; and the Chicago Climate Exchange (CCX), a voluntary carbon reduction and trading program in which commitments become legally binding once a participant joins. Table 2 compares these three programs. Finally, we briefly discuss carbon regulation in Europe and the interaction with renewable energy markets there.

Table 2: Comparison of CA vs. RGGI vs. CCX Carbon-Reduction Strategies

\begin{tabular}{|c|c|c|c|}
\hline & California & RGGI & $\operatorname{ccx}$ \\
\hline Compliance & Mandatory & Mandatory & Voluntary \\
\hline $\begin{array}{l}\text { Emissions } \\
\text { covered }\end{array}$ & $\begin{array}{l}\mathrm{CO}_{2}, \mathrm{CH}_{4}, \mathrm{~N}_{2} \mathrm{O}, \mathrm{PFCs}, \\
\mathrm{HFCs}, \mathrm{SF}_{6}\end{array}$ & $\begin{array}{l}\mathrm{CO}_{2} \\
\text { Possibly more in the } \\
\text { future }\end{array}$ & $\begin{array}{l}\mathrm{CO}_{2}, \mathrm{CH}_{4}, \mathrm{~N}_{2} \mathrm{O}, \mathrm{PFCs}, \\
\mathrm{HFCs}, \mathrm{SF}_{6}\end{array}$ \\
\hline \multirow[t]{2}{*}{ Baseline } & \multirow[t]{2}{*}{1990} & \multirow[t]{2}{*}{$121,253,550$ short tons } & $\begin{array}{l}\text { Phase I members: } \\
\text { Average of annual } \\
\text { emissions from 1998- } \\
2001\end{array}$ \\
\hline & & & $\begin{array}{l}\text { Phase II members: } \\
\text { Same as Phase I, OR } \\
2000 \text { levels }\end{array}$ \\
\hline $\begin{array}{l}\text { Emissions Target } \\
\text { and Date }\end{array}$ & $\begin{array}{l}2000 \text { levels by } 2010 \\
1990 \text { levels by } 2020 \\
80 \% \text { below } 1990 \text { levels } \\
\text { by } 2050\end{array}$ & $\begin{array}{l}\text { Stabilize at "current } \\
\text { levels" by } 2009-2014 \\
10 \% \text { reduction by } 2019 \\
(2.5 \% \text { each year) }\end{array}$ & $\begin{array}{l}4 \% \text { below baseline by } \\
2006 \text { (Phase I) } \\
6 \% \text { below baseline by } \\
2010 \text { (Phase II) }\end{array}$ \\
\hline $\begin{array}{l}\text { Geographic } \\
\text { Scope }\end{array}$ & Statewide & $\begin{array}{l}\text { Northeast U.S. } \\
\text { (currently } 7 \text { states: CT, } \\
\text { DE, ME, NH, NJ, NY, VT) }\end{array}$ & $\begin{array}{l}\text { Primarily N. American } \\
\text { but open worldwide }\end{array}$ \\
\hline Sectors Covered & $\begin{array}{l}\text { All significant sources } \\
\text { of GHG emissions } \\
\text { (includes electricity } \\
\text { sector, others TBD) }\end{array}$ & $\begin{array}{l}\text { Electricity Generators } \geq \\
25 \mathrm{MW}\end{array}$ & $\begin{array}{l}\text { Any "eligible } \\
\text { commercial entity" } 20 \\
\text { who voluntarily opts in }\end{array}$ \\
\hline $\begin{array}{l}\text { Allowance } \\
\text { Distribution }\end{array}$ & TBD & Up to states & Based on baseline \\
\hline $\begin{array}{l}\text { Offsets from RE } \\
\text { Allowed? }\end{array}$ & TBD & No & Yes \\
\hline $\begin{array}{l}\text { Renewable } \\
\text { Energy Support } \\
\text { Fund }\end{array}$ & TBD & $\begin{array}{l}25 \% \text { for strategic energy } \\
\text { purposes (includes } \\
\text { energy efficiency and } \\
\text { consumer rebates) }\end{array}$ & No \\
\hline
\end{tabular}

TBD=to be determined.

\footnotetext{
20 "Eligible commercial entity as defined in Section 1a(11) of the Commodity Exchange Act."

(http://www.chicagoclimatex.com/about/faq.html under "who is eligible," accessed December 13, 2006)
} 
Other states are also eyeing GHG actions, but we do not describe these efforts in detail here, because they are still in early stages of development. ${ }^{21}$ More than half of U.S. states have climate action plans, which seek to address climate change-and this number is growing quickly. ${ }^{22}$ Several states are considering a cap on GHG emissions. For example, Oregon Governor Ted Kulongoski has formed a Climate Change Integration Group to make recommendations for implementing a load-based cap-and-trade program for reducing carbon emissions. ${ }^{23}$ In addition, in 2005, both Arizona and New Mexico set up climate change advisory groups tasked with creating plans to reduce state GHG emissions. In their current forms, these plans mention investigating a regional cap-andtrade system as one of many policy options for reducing GHG emissions in their

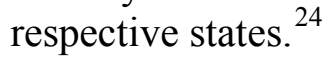

\section{Regional Greenhouse Gas Initiative (RGGI)}

RGGI was initiated in 2003, when New York Governor George Pataki invited 11 Northeast and Mid-Atlantic states to participate in discussions about a regional cap-andtrade system for reducing GHG emissions. In response, nine of those states sent representatives to initiate the discussions: Connecticut, Delaware, Maine, Massachusetts, New Hampshire, New Jersey, New York, Rhode Island, and Vermont. In addition, Maryland, Pennsylvania, the Eastern Canadian Provinces Secretariat, and the Province of New Brunswick sent observers to the talks (RGGI undated).

In August 2003, the states drafted and endorsed an action plan that set program goals. The objective of RGGI is to create a multistate cap-and-trade program to stabilize and then reduce GHG emissions while sustaining affordable and reliable energy, and accommodating the diversity of policies and programs in participating states. ${ }^{25}$

In December 2005, the governors of seven states (all of the aforementioned participating states except Massachusetts and Rhode Island) signed a memorandum of understanding ("MOU") agreeing to implement RGGI. Since then, Massachusetts, Rhode Island and Maryland have indicated that they plan to fully participate, while the District of Columbia and Pennsylvania are evaluating the possibility of joining (Litz 2007, Morgan 2007). Several others continue to observe the process. In August 2006, participating states issued

\footnotetext{
${ }^{21}$ See, for example, the Pew Center on Global Climate Change at http://www.pewclimate.org/what s being done/in the states/ (accessed December 27, 2006).

${ }^{22}$ For a map of states with climate action plans, go to http://www.pewclimate.org/what_s being done/in the states/action_plan_map.cfm, accessed February 15, 2007.

${ }^{23}$ For additional information, see http://www.oregon.gov/ENERGY/GBLWRM/CCIG.shtml, accessed December 13, 2006.

${ }^{24}$ For additional information about Arizona's Climate Change Advisory Group and Arizona's Climate Action Plan, see http://www.azclimatechange.us/index.cfm; and for New Mexico's Climate Change Advisory Group (CCAG) http://www.nmclimatechange.us/index.cfm and draft plan, see http://www.nmclimatechange.us/template.cfm?FrontID=4700, accessed December 13, 2006.

${ }^{25}$ Program goals and guiding principles can be found online at http://www.rggi.org/goals.htm, accessed December 13, 2006.
} 
a Model Rule, which will provide the basis for implementation in the individual states. ${ }^{26}$ The governors of each of the participating states have agreed to propose legislation based on the Model Rule by December 31, 2008. The states will create and maintain a regional organization to oversee administration of the program.

\section{Program details}

RGGI will begin by capping $\mathrm{CO}_{2}$ emissions only, from electricity generating sources that have a capacity of $25 \mathrm{MW}$ or larger. If successful, RGGI may expand to cover other emissions from other sources. It is up to each state to develop specific rules for implementation, within the framework of the Model Rule.

\section{Emissions cap and targets}

Implementation of RGGI will begin in January 2009, at which point the states have agreed to stabilize and cap regional $\mathrm{CO}_{2}$ emissions at current levels (121 million short tons ${ }^{27}$ ) continuing through 2015. Beginning in 2015, the goal is to reduce regional emissions by $2.5 \%$ each year, for a total of a $10 \%$ reduction by the end of 2018 . (See Figure 3) ${ }^{28}$

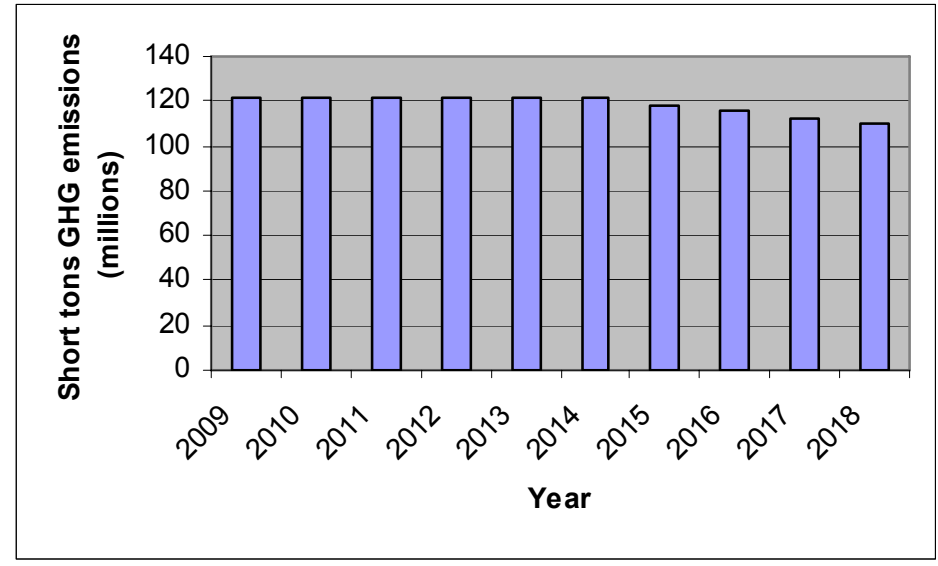

Figure 3: Regional Emissions-Reduction Schedule

\section{Allowances}

The regional emissions budget will be divided among the participating states (see Figure 4). ${ }^{29}$ The states' budgets will remain the same through 2014 , at which point they will ratchet down by $2.5 \%$ each year through 2018 . Each state has the authority to allocate its own emissions allowances (each allowance equals 1 ton of carbon emissions).

\footnotetext{
${ }^{26}$ The MOU and the Model Rule can be found online at http://www.rggi.org/modelrule.htm, accessed December 13, 2006.

${ }^{27}$ A short ton is the U.S. measure of tonnage and is equivalent to 2,000 pounds. This is different from the metric ton, which is larger and approximately 2,205 pounds.

${ }^{28}$ This regional budget covers the seven states that signed the MOU in 2005. As new states join, it will be changed accordingly.

${ }^{29}$ Specific allocations are provided in the Memorandum of Understanding (MOU) on Page 3. The allocations for Massachusetts and Rhode Island will be 26.7 million short tons and 2.7 million short tons respectively (page 8 of the MOU). The MOU can be found online at http://www.rggi.org/docs/mou 12 20_05.pdf, accessed February 18, 2007.
} 
However, each state must use at least $25 \%$ of its allocation for consumer benefits or strategic energy purposes (e.g., energy efficiency programs, customer rebates, and renewables). Methods for allocating the allowances could include any or some combination of the following:

- Directly allocating allowances to generators (using either an input- or outputbased methodology)

- Auctioning allowances to generators (either statewide or regionally with revenues likely used for consumer benefit purposes)

- Distributing allowances to LSEs, who would then sell them to generators (producing revenue which could be used for consumer benefit purposes)

At the end of each three-year compliance period, entities must have allowances equivalent to the amount of $\mathrm{CO}_{2}$ they emitted. They can achieve this by reducing emissions, purchasing allowances from the market, or creating credits through an offset project (discussed below). Entities with a surplus of allowances may either bank them for future use or sell them.

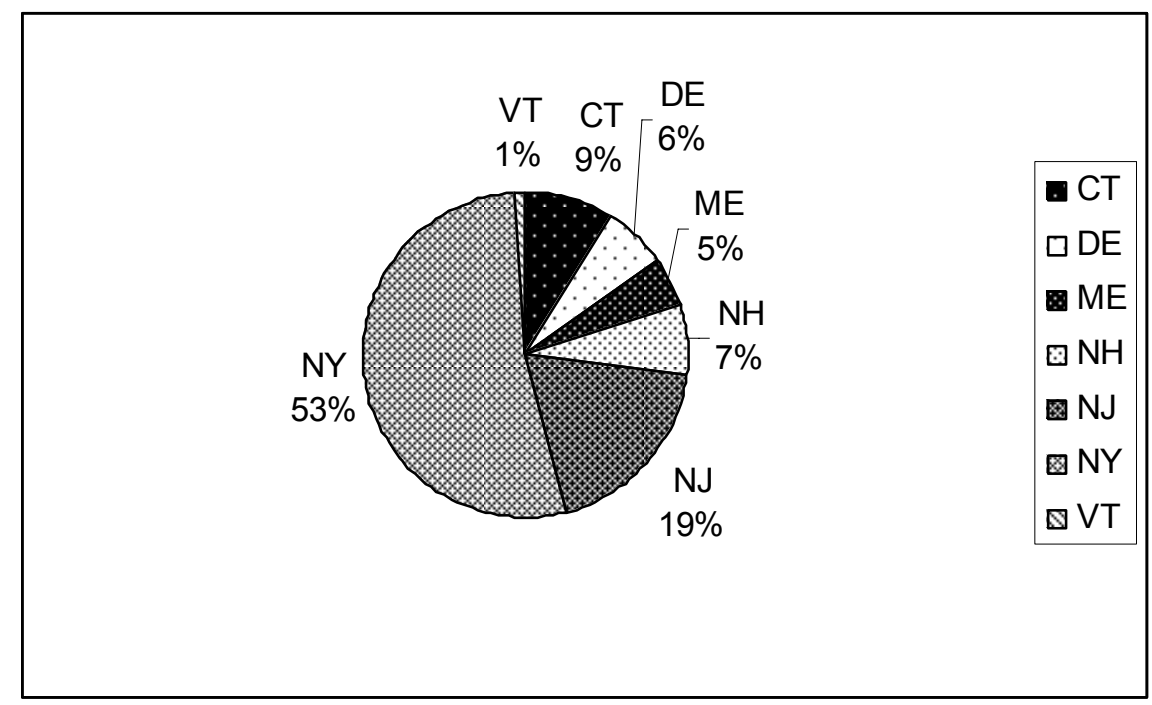

Figure 4: State Share of Regional Emissions

\section{Flexibility mechanisms}

RGGI includes three flexibility mechanisms for entities to achieve their emissionsreduction goals: banking, offsets, and a safety valve. RGGI allows entities to bank allowances for future use without limitation.

RGGI also allows entities to use offsets to account for up to $3.3 \%$ of their total emissions. Offsets can be obtained by investing in GHG emission-reduction projects outside of the electricity sector. These projects can take place within or outside of the RGGI regulated area, but projects outside of the area must follow certain specifications laid out in the 
amended MOU and the Model Rule. ${ }^{30}$ While details of the offset program will be refined, the following types of projects are eligible for creating offsets:

- Landfill methane capture and destruction;

- Reduction in fugitive emissions of sulfur hexafluoride (SF6) from electricity transmission and distribution equipment;

- End-use energy efficiency for natural gas, oil, or propane projects;

- Afforestation; and

- Avoided methane from farming operations

To limit compliance costs, RGGI also includes several "safety valves." For example, if the average annual price of an emissions allowance increases above $\$ 7$, an entity may invest in offsets for $5 \%$ of their total emissions. If the price increases above $\$ 10$, entities may use offsets for $10 \%$ of their reported emissions (at this point, offsets from international projects will also be allowed.) Under these circumstances, the compliance period may be extended as well.

\section{Issues related to renewable energy}

The structure of the RGGI program raises issues for the ability of renewable energy sources to affect overall GHG emissions levels, depending on how states choose to implement it. States have significant discretion in determining how to allocate allowances and, therefore, the effects could vary by state. While states could allocate allowances directly to renewable energy sources through an output-based methodology or set-aside, at the time of writing, a number of states are leaning toward using an auction. For example, New York, Massachusetts, Maine, and Vermont have all proposed auctioning off $100 \%$ of the allowances (Litz 2007). If an auction or other approach is used in which renewable energy sources are not allocated allowances at zero cost, then this will limit the GHG benefit claims that renewable energy sources can make (as discussed in Chapter 3).

The RGGI Model Rule also offers an alternative solution to the GHG benefits claims issue. States may choose to create what RGGI refers to as a "voluntary renewable energy set-aside" in which allowances are retired on behalf of consumers who make voluntary purchases of renewable energy. Under this approach, states would estimate voluntary market purchases at the beginning of each compliance period, and set aside an equivalent number of allowances. Then, at the end of the compliance period, the state would retire allowances equivalent to the actual voluntary REC sales, and true-up any difference between the actual and projected sales in the next compliance period. According to the Model Rule, each MWh of renewable energy purchased should be multiplied by the $\mathrm{CO}_{2}$ emissions rate in the region where the generation occurred. If this is not available, the regulatory agency will need to determine an average emissions rate (RGGI Model Rule 2006). At the time of writing, Maine had included a voluntary renewable energy set-aside in proposed legislation (LD 1090) for implementing RGGI.

\footnotetext{
${ }^{30}$ Offset projects from outside the participating states must occur under the regulatory watch of a cooperating agency in that state. States or other U.S. jurisdictions not participating in RGGI will need to enter into a memorandum of understanding with the RGGI state agencies and agree to incur certain administrative obligations to ensure the credibility of the offset projects.
} 
RGGI includes other provisions that could potentially benefit renewable energy sources. Most significantly, states are required to set aside at least $25 \%$ of allowances for "consumer benefit or strategic energy purposes," such as energy efficiency, renewable, and other clean energy technologies and ratepayer rebates. In fact, some states are considering setting aside more than $25 \%$ of allowances for these consumer benefit purposes. Based on discussions with participating states, it seems unlikely that a state would choose to give these allowances directly to renewable energy sources. A number of states are considering distributing these allowances through some form of auction, where the proceeds are collected and used for consumer benefit purposes. While renewable energy may benefit from a portion of these revenues, some states have suggested that much of the funding would likely go to energy efficiency. Furthermore, while these funds may help provide financial support to renewable energy sources, they would not address the issue of enabling renewable energy purchases to reduce emissions below the cap.

\section{California “Global Warming Solutions Act” and Load-Based GHG Cap}

In June 2005, California Governor Arnold Schwarzenegger signed an Executive Order ${ }^{31}$ establishing GHG emission-reduction targets for the state (see Table 3). ${ }^{\mathbf{3 2}}$ Since then, there has been additional legislation and action by the California Public Utilities Commission (CPUC) to meet these goals. This section will discuss the details of the two most pertinent policies related to potential future carbon cap-and-trade programs - an effort to establish a load-based cap and the Global Warming Solutions Act (AB32), which is now the umbrella legislation covering the state's GHG reduction efforts.

Table 3: State of California's GHG Reduction Targets

\begin{tabular}{|l|l|}
\hline Target Date & Emissions level \\
\hline 2010 & 2000 emissions levels \\
\hline 2020 & 1990 emissions levels \\
\hline 2050 & $80 \%$ below 1990 emissions levels \\
\hline
\end{tabular}

\section{Load-Based Cap and Emissions Performance Standard}

In February 2006, the CPUC issued a decision (D.06-02-032) ${ }^{33}$ stating its intent to establish a load-based cap (a cap placed on load-serving entities rather than individual generators) for the states three investor-owned utilities (Pacific Gas and Electric Company, San Diego Gas \& Electric Company, Southern California Edison Company)

\footnotetext{
${ }^{31}$ Executive Order S-3-05 can be found online at http://www.dot.ca.gov/hq/energy/ExecOrderS-3-05.htm, accessed October 17, 2006.

${ }^{32}$ The Executive Order tasks the Secretary of the California Environmental Protection Agency to coordinate the efforts to meet the targets. There are seven other responsible parties including the president of the Public Utilities Commission and the chairperson of the Air Resources Board (this group is now referred to as the "Climate Action Team").

${ }^{33}$ D.06-02-032 can be found online at http://www.cpuc.ca.gov/PUBLISHED/FINAL DECISION/5372007.htm\#P391 110434, accessed October 17, 2006. D.06-02-032 will be referred to as "the CPUC decision" in this chapter.
} 
and nonutility load-serving entities (LSEs) that provide electric power to customers within the service territories of the aforementioned companies. The goal of the program is to reduce the California electricity sector's impact on climate change and protect ratepayers from elevated prices of electricity caused by costs associated with anticipated carbon regulation. The cap is to be consistent with any future carbon cap-and-trade regimes in the West, nationally or internationally. This is particularly relevant because Governor Schwarzenegger has recently pledged public partnerships with the United Kingdom's Prime Minister Tony Blair and New York's Governor Pataki to investigate linkages between future GHG emissions-trading programs. ${ }^{34}$

The load-based cap covers LSEs rather than power producers, minimizing leakage to other states. In other words, by regulating the emissions portfolios of LSEs, emissions from all of the electric power serving the regulated entities will have to meet the requirements, whether the power comes from California or elsewhere. If the CPUC were to only regulate in-state generators, California could still obtain a large amount of "dirtier" power from outside the state. While the CPUC does not have regulatory control outside of the state, by regulating the LSEs, it causes them to consider the emissions from all of the generators they use to serve their customers.

According to the CPUC decision, the load-based cap will ultimately cover all six major GHGs (carbon dioxide, methane, nitrous oxide, hydrofluorocarbons, perfluorocarbons, and sulfur hexafluoride). Although the allocation method has yet to be determined, the CPUC will allocate allowances in tons of carbon dioxide equivalents $\left(\mathrm{CO}_{2} \mathrm{e}\right)$, which should allow the program to interact with other cap-and-trade programs. The CPUC will also establish a historical baseline (with preference for 1990), create provisions for lowering the cap over time, and establish reporting protocols for the LSEs. The CPUC also plans to investigate "flexible compliance options" such as offsets, trading, banking, and borrowing as well as alternative compliance payments.

Implementation Plan

The CPUC plans to implement its regulatory scheme in two phases to begin controlling GHG emissions as soon as possible, while ensuring that the long-term program is comprehensive and effective. Phase 1 is the creation of a GHG Emissions Performance Standard. After D.06-02-03 was issued by the CPUC, the California Legislature passed SB1368, ${ }^{35}$ which codifies and provides direction for the standard, and applies it to utilities statewide, including municipal utilities. This bill requires the establishment of a GHG Emissions Performance Standard for all base-load generation of LSEs by February 2007 and for all base-load generation of local publicly owned electric utilities by June

\footnotetext{
${ }^{34}$ For additional information about the partnership with the UK, see http://gov.ca.gov/index.php/factsheet/united-kingdom-and-california-announcement-on-climate-change-clean-energy-c/ and the partnership with New York, see http://gov.ca.gov/index.php?/press-release/4449/, accessed December 13, 2006.

${ }^{35}$ For SB1368 status and history, see http://www.leginfo.ca.gov/cgibin/postquery?bill_number=sb 1368\&sess=CUR\&house=B\&author=perata (accessed December 13, 2006). SB1368 will be referred to as "the senate bill" or "the bill" in this chapter.
} 
$2007 .{ }^{36,37}$ Once the standard is in effect, the utilities cannot enter into contracts to purchase power from facilities with emissions that exceed the rate of GHG emissions from a combined-cycle natural gas plant. ${ }^{38}$ Phase 1 will not include market-based mechanisms such as trading emissions credits.

Phase 2, which is currently under development, will focus on the design and implementation of the load-based cap. The LSEs will be responsible for establishing their own baselines and developing a plan for achieving the targeted reductions (which have yet to be established). Reduction strategies may include increasing the amount of renewable generation in the portfolio or reducing emissions at existing facilities. Phase 2 may include emissions trading, but this has not yet been established.

\section{Global Warming Solutions Act - AB32}

In August 2006, the California State Legislature passed AB32 (the Global Warming Solutions Act), ${ }^{39}$ which is designed to reduce the state's impact on global warming. AB32 requires a reduction of statewide GHG emissions to 1990 levels by 2020, beginning in 2012. It covers emissions from electricity consumed in California as well as other "significant" sources of GHG emissions in the state to be determined by the California Air Resources Board (CARB).

AB32 tasks CARB with establishing a statewide GHG monitoring and reporting system, and determining $1990 \mathrm{GHG}$ levels by 2008. CARB will also be responsible for determining early action measures to reduce emissions in the short term (measures to be determined by 2007 and implemented by 2010), and a plan for meeting the target in the most cost-effective manner. The act authorizes CARB to use market-based mechanisms, which could include trading, a carbon tax, or other mechanisms; however, this has not yet been determined. CARB must put regulations in place to meet the target by 2011, and the regulations will be effective beginning in 2012 (see Table 4 for a timeline).

Among other things, the regulations will determine how allowances should be allocated, if applicable, and will give credit to those entities that took early action. The regulations must be designed to minimize leakage of emissions out of state; not interfere with federal and state efforts to reduce other toxic emissions; and ensure GHG reductions are real, quantifiable, and verifiable — and that they are new and would not have otherwise occurred. CARB must work with the CPUC so that reduction measures for electricity are not "duplicative or inconsistent with regulatory requirements."

\footnotetext{
${ }^{36}$ The CPUC does not regulate municipals, therefore municipals will report to the Energy Commission. The requirements are expected to be essentially the same.

${ }^{37}$ The CPUC adopted an interim Emissions Performance Standard (EPS) on January 25, 2007, that enables renewable energy sources to meet the EPS even if they do not retain their RECs.

http://www.cpuc.ca.gov/static/energy/electric/climate+change/060419 ghg emissionscap.htm (accessed

February 20, 2007).

${ }^{38}$ The EPS will apply to all new generation and new or renewed contracts with a term of five or more years.

${ }^{39}$ The final text for AB32 can be found online at http://www.arb.ca.gov/cc/docs/ab32text.pdf (accessed December 13, 2006).
} 
Table 4: AB32 Deadlines

\begin{tabular}{|l|l|}
\hline Target Date & Task \\
\hline 2007 & $\begin{array}{l}\text { California Air Resources Board (CARB) must determine early action } \\
\text { measures }\end{array}$ \\
\hline 2008 & CARB must establish monitoring and reporting system \\
\hline 2008 & CARB must determine 1990 GHG emissions levels \\
\hline 2009 & $\begin{array}{l}\text { CARB must have plan for meeting targets in the most cost-effective } \\
\text { manner }\end{array}$ \\
\hline 2010 & Meet deadline for implementing early action measures \\
\hline 2011 & Regulations for meeting targets must be in place \\
\hline 2012 & Affected entities begin to phase in GHG limits \\
\hline 2020 & Reach 1990 emissions levels \\
\hline
\end{tabular}

As stated earlier, AB32 now acts as the umbrella regulation for the CPUC's effort to create a load-based cap. The CPUC is working with CARB and began planning in late 2006 how the utilities will meet AB32 targets. The CPUC has issued a schedule that calls for a final decision by the end of 2008. The schedule covers issues such as reporting, establishing baselines, allowance allocation options, the design of the cap structure, and flexible compliance mechanisms (Tom 2007).

Issues related to renewable energy

Because it is still early in the design process for California's GHG regulatory systems, it is difficult to determine how much of an influence these programs will have on renewable energy markets. The issue of whether renewable energy generators will be able to demonstrably and directly reduce GHG emissions will depend on the policy structure. Regulators will need to address how the voluntary market will interact with the new mandatory requirements, and whether voluntary purchases would be in addition to reductions achieved by the cap. If the policy is designed so that a renewable energy source that has sold off its RECs in the voluntary market would result in system power that needs an allowance, then a voluntary purchase would have the effect of reducing emissions below the cap.

\section{Chicago Climate Exchange}

The Chicago Climate Exchange $(\mathrm{CCX})^{40}$ is North America's only active voluntary-but legally binding - integrated trading system to reduce emissions of all six greenhouse gases, with offset projects worldwide. Created in 2000 as a pilot project of Northwestern University's Kellogg Graduate School of Management, with funding from the Joyce Foundation, CCX is designed to create a market for trading emissions allowances and offsets with price transparency and environmental integrity. CCX also aims to build the framework and infrastructure needed to cost-effectively manage GHG emissions through the experience and education of participants and the public. Under the program,

\footnotetext{
${ }^{40}$ See http://www.chicagoclimatex.com/. CCX has also formed the New York Climate Exchange and the Northeast Climate Exchange in anticipation of the implementation of RGGI; and CCX recently announced the establishment of the Montreal Climate Exchange (CCX March 2006; July 2006). The European Climate Exchange, a sister organization of CCX, currently handles $80-90 \%$ of the exchange-traded volume traded in the EU ETS (CCX March 2006).
} 
members ${ }^{41}$ — which include municipalities, states, universities, power providers, agricultural organizations, and large corporations - make commitments to reduce their GHG emissions. Those who reduce below the targets have surplus allowances to sell or bank; those who emit above the targets comply by purchasing CCX Carbon Financial Instrument (CFI) contracts. Trading began in 2003, making CCX the only GHG trading market in North America, and currently the only trading market in the world for all six GHG emissions and multiple sectors.

\section{Membership Categories}

New members can join CCX at any time under one of the following four membership categories $^{42}$ :

- CCX Members (Emitting Members) - have direct GHG emissions in the United States, Canada, or Mexico

- CCX Associate Members - have insignificant or no direct GHG emissions, and comply with CCX requirements by purchasing emissions allowances to offset all indirect emissions associated with a set of business-related activities (e.g., employee travel).

- CCX Exchange Participants - acquire and retire emissions credits

- CCX Participant Members - include both Offset Providers and Liquidity Providers (entities without significant GHG emissions), the latter of which trade or engage in market-making activities on the exchange, for purposes other than compliance with the CCX reduction schedule.

\section{Emissions Targets, Trading, and Baseline}

In Phase I, each member committed to reducing emissions by $1 \%$ per year below an established baseline from 2003-2006, for a total of a $4 \%$ reduction by 2006 . In Phase II, which extends from 2007 to 2010, all members must reduce emissions 6\% below their baselines by $2010 .{ }^{43}$ Allowances, or CFI contracts, are the currency of exchange and represent 100 metric tons of $\mathrm{CO}_{2}$ equivalent. Members receive allowances based on their baseline emissions and their reduction schedule.

Baseline emissions for Phase I members are the average emissions from their facilities from 1998-2001. New Phase II members will establish the same baseline, or may choose to use emission levels from 2000.

Phase I trading concluded in December 2006 and emissions trading for Phase II began in April 2006. The following month, CCX experienced record trading volume: Roughly 2.5 million metric tons of $\mathrm{CO}_{2 \mathrm{e}}$ were traded by the middle of May, accounting for a full onethird of the cumulative trading volume since December 2003 (CCX May 2006).

\footnotetext{
${ }^{41}$ Any entity that qualifies as an "Eligible Commercial Entity," as defined in Section 1a(11) of the Commodity Exchange Act, may access the CCX Trading Platform. For additional information, see http://www.chicagoclimatex.com/about/faq.html, accessed December 13, 2006.

${ }^{42}$ See http://www.chicagoclimatex.com/about/members.html for examples of companies in the different membership categories.

${ }^{43}$ Members joining in Phase II have the same target and, therefore, more aggressive annual goals from 2007-2010 than members that began their reductions in Phase I.
} 
Flexibility Mechanisms: Banking and Offsets

CCX incorporates two flexibility mechanisms: banking and offsets. If members have excess allowances in a given year, they may choose to sell them to other members, or bank them for future use. Members may use extra allowances from previous years for compliance, but they may not use allowances from future years to meet existing-year compliance targets (e.g., they cannot use CFIs with a 2006 vintage year in 2005). Net sales and banking are limited, subject to the rules outlined in the CCX Rulebook.

Members may also purchase CFIs from registered offset projects to count toward their emission caps. Offsets can be obtained from the following types of projects: forestry, agricultural (including soil carbon and methane emissions), landfill methane emissions, renewable energy, and clean development mechanism eligible projects. ${ }^{44}$

For renewable energy projects to count as an offset under CCX, the RECs and associated green attributes must be retired (for the portion of the project output sold into CCX). Therefore, the same output of these projects cannot be resold in voluntary markets or used for compliance with a state RPS. The amount of emissions offset from renewable energy projects are calculated based on the GHG emission rate of a combined-cycle natural gas plant, 0.4 metric tons of $\mathrm{CO}_{2}$ per MWh (CCX June 2006 and CCX February 2006).

Owners of eligible offset projects may join CCX and sell offsets directly into the market, if they meet a certain threshold level; or they may sell the emissions offsets to an offset aggregator, who will then package the offsets from several projects for sale on CCX.

Issues related to renewable energy

CCX interacts with renewable energy markets on a number of levels. First, it provides another voluntary market for the output of renewable energy projects, because renewables are eligible to create offsets under CCX. While this is an opportunity for renewables, few, if any, renewable energy projects have been used to provide offsets to date because REC markets have generally provided greater revenue; although higher prices under CCX most recently have made CCX a more attractive option. For example, prices for renewables under CCX have ranged from about $\$ 1 / \mathrm{MWh}$ to $\$ 2 / \mathrm{MWh}$ most recently, as compared to $\$ 1 / \mathrm{MWh}$ to $\$ 5 / \mathrm{MWh}$ in the voluntary REC market. ${ }^{45}$ As mentioned above, in order to participate in CCX, renewable sources must include all of their environmental attributes (and RECs) and cannot be used for other purposes (e.g. to meet an RPS); therefore, renewables have to choose in which market to participate.

Going forward, price competition from other types of eligible offset projects and prices in RPS and voluntary renewable energy markets will determine the role of renewables in the CCX.

\footnotetext{
${ }^{44}$ For information about specific types of offset projects, see http://www.chicagoclimatex.com/environment/offsets/index.html, accessed December 14, 2006.

$\frac{}{45}$ These calculations are based on the rate used by $\mathrm{CCX}$ to calculate displaced $\mathrm{CO}_{2}$ emissions for renewable projects ( 0.4 metric tons of $\mathrm{CO}_{2}$ per $\left.\mathrm{MWh}\right)$ and recent market prices for carbon under $\mathrm{CCX}$ and voluntary market RECs (excluding solar). See Chapter 3 for more information on market prices.
} 
On the other hand, CCX facilitates a certain degree of competition for renewable energy markets to the extent that emission reductions sourced from projects other than renewable energy (i.e., methane capture and destruction, soil carbon sequestration) under CCX are used to supply voluntary carbon offset products, which may be marketed in direct competition to green power products. For example, a number of organizations - such as TerraPass, DriveNeutral, and Carbonfund.org - acquire and retire CFIs from CCX to supply carbon-offset products that they market to end-use consumers who want to offset the GHG emissions released through their daily activities. These products are marketed in direct competition to pure green power products. To the extent that CFIs are derived from efficiency and other eligible projects, these create competition for renewable energy as a carbon-reduction strategy. However, some carbon-offset marketers include RECs (in addition to other carbon reduction projects) in the portfolio of offsets, which supports the market for renewables.

\section{European Union (EU)}

Unlike the United States, the European Union (EU) has signed the Kyoto Protocol, and all of the member countries have made national commitments to $\mathrm{CO}_{2}$ reduction. Entities trade carbon credits on the European Union Emissions Trading Scheme (ETS), which is currently the world's largest carbon-trading regime. From April 2005 to November 31, 2006, more than 500 million metric tons of carbon had been traded through the European Climate Exchange (ECX) (ECX 2006). The ETS currently only allows trades for $\mathrm{CO}_{2}$, with the option to expand to other GHG emissions in the future. The trading scheme only covers large emitters in a few industries, including power and heat. Each country has a National Allocation Plan that sets targets for individual companies. There are 12,000 plants currently registered to trade, and companies that fail to meet their targets will be fined (Moody 2006).

In Europe, the carbon market is separate from renewable energy markets, and renewable energy does not receive allowances for carbon under the ETS. The rationale is that renewables emit no carbon, and therefore do not need allowances. Further, including renewables could lead to double-counting of emissions benefits. ${ }^{46}$ Finally, there are other policies in effect supporting renewables such as feed-in tariffs, quota obligation systems (similar to an RPS), and disclosure statements. While some countries took into account the amount of new renewable energy generation that would result from existing renewable energy policies when setting the $\mathrm{CO}_{2}$ target, this is not the case for all of the countries participating in Kyoto. In the countries that did, renewable sources could claim a reduction in $\mathrm{CO}_{2}$ (Ölz et al. 2006). Renewables are also seen as benefiting in the ETS, due to the indirect advantage they could receive as power prices increase for fossil fuel generators (Schneiders 2006, Kristiansen 2006, Moody 2006).

\footnotetext{
${ }^{46}$ See Ölz et al. 2006 for further discussion on the issue of double-counting.
} 
REC markets also exist in Europe where countries use RECs to meet EU or individual country renewable energy targets, and for voluntary markets. ${ }^{47}$ A REC can be used to calculate $\mathrm{CO}_{2}$ emission reductions; however, a REC does not include carbon (Moody 2006, Schneiders 2006). A REC is primarily a tracking tool, or proof that electricity was generated from a renewable energy source in a certain origin. A REC can also represent other benefits that renewables provide, such as a lack of $\mathrm{SO}_{2}$ and $\mathrm{NO}_{\mathrm{x}}$ emissions, fuel diversity and economic development (Moody 2006, Ölz et al. 2006)

At this time, there is no clear evidence that the ETS has had an impact on the voluntary renewable energy market (Niermeijer 2006). Lack of research and data with respect to this question makes it difficult to assess any potential impacts. ${ }^{48}$ Some market participants have suggested that consumers are not concerned about whether their purchases include a direct reduction in carbon, but are comfortable with the fact that they are supporting the development of emissions-free power production (Moody 2006). In other words, consumers want clean energy and the additional benefits that renewables and RECs supply (e.g., fuel diversity, energy security, distributed generation, and development of the renewables industry) and not necessarily carbon rights. However, at least one recent news article suggests that consumers may think their purchases affect carbon levels and are confused about the benefits of green power products. ${ }^{49}$

Even if it is the case that the European voluntary renewable energy market is unaffected by the inability of renewable energy purchasers to reduce overall carbon levels, this policy design does not provide a good model for the United States voluntary market. Many U.S. entities that make voluntary renewable energy purchases do care about the climate impact and are purchasing renewables at least, in part, because they want to reduce their carbon footprint (as discussed in Chapter 2).

\footnotetext{
${ }^{47}$ The EU Renewable Energy Directive 2001/77/EC established indicative targets for each country; there is no sanction if a country misses its target. How each country achieves its target is its own decision, but generally includes either feed-in tariffs, quota systems (similar to RPS), or tax incentives.

${ }^{48}$ Recently, the Netherlands reported a significant decline in green power customers, but the losses have been attributed to increasing prices rather than lack of carbon benefits - initially, green power was offered at prices below conventional power because of the availability of tax incentives. Greenprices, "Dutch Green Power Market Decreased by 20\% in Two Years," December 21, 2006.

http://www.greenprices.com/eu/index.asp, accessed January 8, 2007.

49 "Consumers 'confused' by green energy tariffs," December 14, 2006, Guardian Unlimited, http://money.guardian.co.uk/news_story/0,1972369,00.html, accessed January 8, 2007.
} 


\subsection{Policy Design Options}

As discussed in Chapters 3 and 4, cap and trade is emerging as a form of carbon regulation at the state and regional levels. The timing, scope, and form of federal action is unknown at this time; but the precedent of state cap and trade, combined with precedentsetting federal cap-and-trade regulation of $\mathrm{SO}_{2}$ and $\mathrm{NO}_{x}$, suggests that cap and trade will be considered as part of any federal action.

On the assumption that carbon regulation will incorporate a cap-and-trade approach, our focus in this section is on cap-and-trade policy options that would enable voluntary renewable energy markets to thrive. ${ }^{50}$ We recognize that there are broader issues with respect to the design of cap-and-trade programs - such as sectors capped, covered emissions, the level of the cap and flexibility mechanisms - but here we focus on how cap-and-trade regulation can be accomplished while addressing the needs of voluntary renewable energy markets. ${ }^{51}$

The discussion of policy options in this chapter is not intended to include a comprehensive treatment of allowance allocation methods. Indeed, some of the approaches discussed here are independent of the method of allocation.

In the absence of renewable generators being allocated allowances, marketers could purchase allowances so that claims can be made with their retirement (as discussed in Chapter 3). This is not a general policy solution to the environmental claims issue, however; for that, we turn to some other cap-and-trade design and implementation concepts that would enable renewable energy sources to affect emissions levels.

\section{Set-Aside Allocations to Renewable Generators}

Ensuring that renewable energy generators are allocated allowances is the most direct way to credit renewable generation with the emissions benefits they provide under a capand-trade program. A renewable generator can convey an allowance with the sale of renewable energy or RECs, and the retirement of the allowance is a clear basis for making an emissions-reduction claim.

One approach for allocating allowances to renewable generation is through a set-aside. With this approach, regulators specify — or set aside — a certain percentage of total allowances to be granted for defined eligible activities, usually renewable energy and energy efficiency. Renewables do not compete with emitting fossil plants for the setaside allowances, but they must apply for them and demonstrate that they are eligible and meet other criteria.

\footnotetext{
${ }^{50}$ The main alternative approach to emissions reduction that is sometimes mentioned - a carbon tax - does not create the same concerns for voluntary markets.

${ }^{51}$ For a broader discussion of cap-and-trade program design issues, see U.S. EPA (2003).
} 
Set-asides have been established under the $\mathrm{SO}_{2}$ cap-and-trade program and the federal $\mathrm{NO}_{\mathrm{x}}$ budget-trading program. ${ }^{52}$ Under the latter program, seven states have adopted setasides for renewables and energy efficiency. ${ }^{53}$ Under the new CAIR trading program for $\mathrm{NO}_{\mathrm{x}}$, several additional states are likely to include renewables through a set-aside approach (Salerno 2006).

While set-asides have been used to date in conjunction with free allocations to emitting facilities, the set-aside approach could also work with an allowance auction. ${ }^{54}$ In this case, the set-aside would be available to eligible activities, such as renewable generation, while the remainder of allowances would be auctioned. The revenue from auctioning allowances could also be used to support renewable energy development, although an auction by itself would not enable claims of emission reductions.

With respect to renewable energy markets, there are several main advantages to the setaside option.

- Purchasers of the renewable energy, or RECs, with the allowances can make a strong and substantiated claim to have reduced emissions if they then retire the allowances.

- Renewable generators that acquire allowances through the set-aside can monetize the value of the allowances either in a higher-priced REC or by selling the allowance separate from the REC.

- In addition, there is significant experience with implementing set-asides for renewable energy and efficiency.

There are also several potential disadvantages of set-asides for renewable energy markets. $^{55}$

- Renewable generators have to apply for the allowances rather than obtaining them automatically as emitting sources do. The application and approval process adds cost and uncertainty to obtaining allowances.

- Revenue from allowances could attract better terms for renewable project finance, but uncertainty about whether a particular project will receive allowances over the long term may reduce the allowance value for project finance.

- The set-aside pool of allowances may not be big enough, especially if renewable generation grows.

- There is no guarantee that the emissions allowances will remain bundled with the renewable energy or RECs. Generators could sell them to emitters instead. Therefore, buyers will have to be more informed and discriminating about environmental

\footnotetext{
${ }^{52}$ The Title $\mathrm{IV} \mathrm{SO}_{2}$ trading program provided a set-aside (the Conservation and Renewable Energy Reserve) for renewables but was little-used, for several reasons: The price of allowances was lower than anticipated, providing little economic incentive to take advantage of the set-aside; the program did not provide a long-term incentive - only renewables that came online before 2000 were eligible; only utilities were eligible to get allowance from the set-aside; and the award of one allowance for $500 \mathrm{MWh}$ of generation did not reflect the emissions actually avoided. See Wooley and Morss 2001.

${ }_{53}$ These states are Indiana, Maryland, Massachusetts, Missouri, New Jersey, New York, and Ohio. (U.S. EPA 2005)

${ }_{55}^{54}$ For more on allowance auctions, see EPA (2003) and RAP (2006).

${ }^{55}$ See Bluestein et al. 2006 for additional discussion.
} 
products because some RECs in the market will have emissions benefits and others will not.

Possible solutions to some of these concerns could include a periodic increase to the setaside amount as demand grows, and a 5- to 10-year commitment of allowances that are approved by the set-aside administrators.

\section{Output-Based Allocations to Renewable Generators}

Output-based allocation is another way to allocate allowances to renewables. With output-based allocations, allowances are granted to generators based on the quantity of electricity produced by each electric generator under the cap. Allocations are made proportionately to a generator's percentage of the total generation times the pool of allowances available for the allocation period. A renewable generator could, thus, earn its proportionate share of allowances and sell them to emitters who need them, or sell them for retirement with its RECs.

There is some precedent for output-based allocation. The EPA's Clean Air Interstate Rule (CAIR) includes a partial output-based allocation for new sources (post-2001); however, the allocation applies only to fossil-generating units. ${ }^{56}$ Both Wisconsin and Pennsylvania have proposed a full output-based allocation, including to renewables, under CAIR (Wisconsin 2006, Pennsylvania 2007). Both of these states would allocate, based on output, to new renewables that commenced operation after a specified date.

As to output-based allocation of allowances under $\mathrm{CO}_{2}$ cap and trade, such programs are just emerging. Output-based allocation was discussed in the development of RGGI, but the RGGI Model Rule does not specify a particular allocation approach. Instead, states can choose their own approach to allocating allowances. However, none of the RGGI states has yet proposed an output-based allocation, and several states have indicated an interest in auctioning all allowances.

However, output-based allocation, in general, is not necessarily a solution to emissionreduction claims by renewable generators. For this approach to work for renewable generators, the cap-and-trade rules must specify that renewable generators are eligible to receive allowances.

According to the U.S. EPA, there are several generic benefits of output-based allocation that go beyond the inclusion of renewable energy. First, output-based allowances encourage energy efficiency at the plant level, because generators make more money if they can minimize their fuel input while maximizing electricity output. Second, because output-based emission regulations promote increased fuel-conversion efficiency and a

\footnotetext{
${ }^{56}$ The Clean Air Interstate Rule (CAIR) caps emissions of sulfur dioxide $\left(\mathrm{SO}_{2}\right)$ and nitrogen oxides (NOx) in 28 eastern states and the District of Columbia. For additional information, see http://www.epa.gov/cair, accessed December 14, 2006. EPA already allocated emission allowances for $\mathrm{SO}_{2}$ to sources subject to the Acid Rain Program; however, for the NOx trading program, the affected states may allocate their allowance budget as they see fit.
} 
corresponding reduction in fuel consumption, they promote pollution prevention and reduced multipollutant emissions. Third, output-based approaches provide a transparent measure of the emissions impact of generating electricity because they take into account the output and efficiency of the production process. This facilitates "apples to apples" comparisons of the emissions impacts of different facilities. ${ }^{57}$

On the other hand, awarding allowances based on output creates a subsidy for production. Encouraging output in this way may result in lower wholesale prices (which is good for consumers), but may lead to less energy efficiency at the end-use level if electricity is cheaper.

More specifically to renewable energy markets, advantages of output-based allocation include the following.

- Purchasers of the renewable energy, or RECs, with the allowances can make a strong and substantiated claim to have reduced emissions if they then retire the allowances.

- Renewable generators that acquire allowances through the set-aside can monetize the value of the allowances either in a higher-priced REC or by selling the allowance separate from the REC.

- Once the rules are set, this allocation is more reliable and incurs less transaction cost than a set-aside approach (Bluestein et al. 2006).

Output-based allocation, like an allowance set-aside, does not provide an automatic solution for emission-reduction claims by voluntary purchasers, if renewable energy generators sell allowances in the carbon market and do not include them with the REC. If this occurs and some RECs include allowances and others do not, buyers will have to be much better-informed and more discriminating.

\section{Load-Based Cap}

Under traditional cap-and-trade programs, allowances are allocated to the sources of emissions, or power generators. Instead of placing an emissions cap on generators, a load-based approach focuses on the portfolio of resources used to serve demand. A loadbased approach would place an emissions cap on the generation portfolio used to serve retail or end-use load, and would allocate allowances to the utilities or competitive electricity providers - generically, load-serving entities (LSEs). The LSEs would have to obtain enough allowances to cover the emissions of their portfolio of sources - the power plants from which they buy. If the cap is set low enough, LSEs would be motivated to acquire resources that have zero or low emissions.

Some argue that allocating allowances to emitting power plants is appropriate for $\mathrm{SO}_{2}$ or $\mathrm{NO}_{\mathrm{x}}$ because generators have technology options available to reduce emissions (such as

\footnotetext{
${ }^{57}$ For additional information, see http://www.epa.gov/chp/state resources/output based_reg.htm, accessed December 14, 2006. For more detail, see U.S. EPA, Office of Atmospheric Programs, Climate Protection Partnerships Division, Output-Based Regulations: A Handbook for Air Regulators. Draft final report prepared by ERG and Energy and Environmental Analysis Inc., August 2004. http://www.epa.gov/chp/pdf/OBR_final 9-1-05.pdf, accessed December 14, 2006.
} 
scrubbers or selective catalytic reduction), but that individual generators have few options to reduce $\mathrm{CO}_{2}$ emissions (RGGI 2004). Under a load-based cap, however, LSEs can reduce their $\mathrm{CO}_{2}$ emissions by choosing a less-emitting generation portfolio, including emissions-free renewable energy.

There are several differences between a load-based cap and a cap on generator emissions.

- If a load-based cap is being implemented by a state (or group of states) rather than the national government, it can affect generators located out of state that want to sell into the regulated state or region. ${ }^{58}$ With a cap on generator emissions, by contrast, the state's authority would extend only to generators located within their jurisdiction.

- A consequence of the load-based cap is that it aligns the motivation of the LSEs to obtain cleaner resources with support for renewable energy. Because LSEs have to meet an emissions cap on their portfolio, they will compete for the zero-emitting resources, increasing the value of such resources. ${ }^{59}$

- Although a load-based cap motivates LSEs to buy renewable energy or RECs, it does not provide an additional revenue stream to renewable generators. That may not matter if the demand for emission-free energy drives up the value of renewable generation, but it is unclear whether this added value would be equivalent to the revenue that might be derived if a renewable generator were to receive allowances under a generator cap.

As with any major policy, whether the policy has the intended effects depends on the detailed rules. If RECs are used, some convention must be adopted to assign attributes to the underlying energy. When RECs are unbundled from electricity, the underlying electricity is left with no attributes (sometimes called "null" energy). If this null energy is assigned the state or regional system average attributes (including emissions), it would ensure that every MWh sold to end-users has an environmental profile. ${ }^{60}$ If the LSE is allowed to use the null energy without assigning any attributes, the one-to-one relationship between retail sales of energy and environmental attributes is lost, and it creates the functional equivalent of an emissions-free $\mathrm{MWh}$, which would be doublecounting. By assigning system average attributes to null electricity, an LSE using that energy would have to acquire the necessary allowances to cover the emissions.

If regulators use this approach, it would enable environmental claims by voluntary purchasers of RECs. If RECs are sold to voluntary purchasers, the resulting null energy would be assigned system attributes so that any LSE using that MWh will have to have

\footnotetext{
${ }^{58}$ Even a national load-based cap could affect the desirability of importing energy from generators outside the United States.

${ }^{59}$ Contrast this effect with a cap on emitting generators, which increases the cost of fossil generation relative to renewable generation. The relative cost is an incentive for LSEs to buy renewable generation. Whether one effect is stronger in favor of renewables than the other is not clear.

${ }^{60}$ This is very similar to states with environmental disclosure requirements where energy without attributes is assigned system average attributes on the date that electricity labels are created.
} 
an allowance to cover its emissions. That takes another allowance out of the allowance budget (causing a reduction somewhere else in the system), and enables a voluntary purchaser to claim to have reduced emissions.

Depending on how these issues are resolved, the load-based approach offers another potential option for supporting claims by voluntary purchases of renewable energy.

A load-based cap is being considered on the West Coast by both California and Oregon. As discussed in Chapter 4, the California Public Utilities Commission (CPUC) proposed to regulate $\mathrm{CO}_{2}$ emissions from its three investor-owned utilities in two phases. The first phase would be a performance standard for any new power plants or new contracts for power, while the second phase anticipates a cap on emissions from the resource portfolios of each regulated utility. The recent approval of SB1367 and AB32 in California seems to confirm this approach, and extend it to municipal utilities as well.

A major hurdle for a load-based cap is that it has not been tested and implemented. As a result, there are many details yet to be worked out. States considering a load-based cap need to decide whether voluntary renewable energy would count toward meeting the cap, and what attributes would be assigned null energy if RECs are used to verify the portfolio. The resolution to these issues will determine not only what claims voluntary purchasers can make, but also whether consumers are motivated to purchase renewable energy.

In summary, the advantages of a load-based cap to renewables include the following.

- A load-based cap aligns the motivation of the LSEs to obtain cleaner resources with support for renewable energy.

- A load-based cap may support emission-reduction claims, depending on rules.

On the other hand, there are some disadvantages.

- The approach is untested and many details remain to be worked out to enable an emissions-reduction claim.

- A load-based cap would not provide renewables with an opportunity to receive revenues in emissions markets because they would not receive allowances.

\section{Reduce the Cap to Account for Renewable Energy Demand}

Another approach that would enable renewables to make GHG emissions benefits claims is if regulators consider demand for renewable electricity when setting the cap, or periodically reduce the cap to reflect growing demand for renewable electricity. Renewable energy demand could include both mandatory demand from state RPS policies as well as projected voluntary demand from retail consumers purchasing differentiated green power products.

Periodic reductions in the cap could be based on either projected demand or on actual demand after the fact. In setting the RGGI emissions cap, for example, analysts modeled the projected renewable energy generation needed to meet state RPS targets. Setting the 
cap, however, was not based directly on this projected demand. As described by one participant, modeling this energy demand reduced the economic impacts of various cap levels; but, ultimately, the cap was set by a policy and political exercise that balanced numerous factors including electricity price impacts, price uncertainty, emission reductions, projected emissions leakage, among other things (Sherry 2007).

This experience suggests that reducing emissions caps based on projected demand for renewable energy would be difficult to achieve.

To the extent that reluctance to reduce the cap is based on uncertainty about future demand, the cap could be adjusted based on reported voluntary and/or mandatory demand for renewable energy that has already occurred. After-the-fact data on demand would be readily available from regional energy certificate tracking systems, or from state RPS programs and marketers of differentiated products for which they want to make environmental claims. Actual data, being more reliable and credible than projected demand, might facilitate a political agreement allowing emissions caps to be periodically reduced.

The advantages of adjusting the cap, from a renewable energy markets perspective, include the following.

- Reducing the cap based on demand for renewable energy would clearly reduce emissions.

- Retrospective claims could be made by renewable generators that came online in the years leading up to the cap reduction.

There are also disadvantages for renewable energy markets.

- It is uncertain whether ratcheting down the cap would actually occur because it would be subject to a political debate each time the cap is reconsidered.

- Prospective claims would be tenuous based on expected action to reduce the cap.

- Adjusting the cap does not provide an opportunity for renewable generators to obtain revenues in emissions markets because they would not receive allowances.

\section{Retire Allowances on Behalf of Renewable Energy Sales}

Another possible approach is for regulators to consider demand for renewable electricity and reduce the number of allowances allocated to emitters accordingly. This method focuses on retiring allowances after the cap is established, which may not be subject to the same political debate that might occur when trying to adjust the cap.

This approach could apply to renewable energy demand from state RPS policies as well as projected voluntary demand from retail consumers purchasing differentiated green power products. Adjustments could be based on either projected demand or on actual demand, after the fact. In this manner, renewable generators would not actually receive allowances, but they could still claim to reduce emissions because some emission allowances would never enter circulation and would be retired on their behalf. 
This approach was discussed as part of the RGGI planning process. And, in comments on the draft Model Rule, the Center for Resource Solutions, the Pace Law School Energy Project, and the Union of Concerned Scientists (UCS) all requested that the Model Rule retire allowances on behalf of voluntary demand. ${ }^{61}$ In particular, UCS commented:

"Therefore, to sustain and encourage these markets, we believe it is critical that the $\mathrm{CO}_{2}$ benefits of renewable energy, which derive from displacement of emitting sources in the RGGI region, be recognized... [the Model Rule should] forecast voluntary demand and subtract the resulting emission reductions from the cap. The forecast would be for each three-year period, and would be trued up by examining the number of RECs retired for voluntary market purposes. This information is available with the cooperation of the regional certificate tracking systems - the NEPOOL Generation Information System (GIS), the PJM Generation Attributes Tracking System (GATS), and the New York Environmental Disclosure Program (EDP)." (UCS 2006)

The final RGGI Model Rule was revised to take voluntary demand into account, but leaves it to the discretion of each participating state, as discussed in Chapter 4. Under $\mathrm{CO}_{2}$ Allowance Allocations, the Model Rule states, "The following subdivision is an optional voluntary renewable energy set-aside provision. It represents one way a state could implement such a set-aside.” (RGGI 2006)

The provision, if adopted by a state, would allow any person to submit data documenting purchases of voluntary renewable energy prior to a three-year control period. Based on this information, the state agency responsible for regulating the cap-and-trade program would then project voluntary demand for the coming three-year control period and hold equivalent allowances in a set-aside or reserve account. ${ }^{62}$ At the close of the control period, the regulatory agency would retire allowances from the set-aside based on actual voluntary purchases and the relevant emissions factors. If actual purchases are greater than projected, the difference will be added to the projection for the new control period; and, if less than projected, the difference will be subtracted from the projection for the new control period.

The RGGI approach does not actually lower the cap, but it has a similar effect by taking allowances associated with projected voluntary demand off the top of the cap and then setting them aside before allocating the remaining allowances. These reserved allowances are later retired based on actual purchases, with the desired effect of reducing $\mathrm{CO}_{2}$ emissions. If adopted by the states into their own rules, this could preserve the ability of renewable energy marketers to claim that purchases will reduce emissions.

\footnotetext{
${ }^{61}$ All comments on the draft Model Rule may be found at http://www.rggi.org/stakeholder_comments model rule.htm, accessed December 14, 2006.

${ }_{62}$ Although called a set-aside in the Model Rule, this is not the same as the previous description of a setaside, in which a renewable generator may apply for and receive allowances. In that case, the generator may sell or retire the allowances; whereas, in this case, the regulatory agency retires the allowances on behalf of consumers purchasing the renewable energy.
} 
At the time of writing, Maine had included this option to retire allowances on behalf of voluntary renewable energy demand in proposed legislation (LD 1090) for implementing RGGI, but it is too early to know whether other RGGI states will include this approach in their rules.

Retiring allowances on behalf of renewable energy sales has some advantages to renewable generators and markets.

- It provides direct and clear support for emissions-reduction claims for voluntary renewable energy demand.

- Reserving and retiring allowances for renewable energy reduces allowances available to emitters in the market, driving up demand for low- or zero-emission generation sources.

- The approach provides flexibility for the number of emissions allowances to grow as demand grows, unlike the fixed set-asides used in some state $\mathrm{NO}_{\mathrm{x}}$ programs.

The disadvantages of this approach include the following.

- Transaction costs could discourage marketers or others from estimating demand and then later proving the sales.

- Marketers, in particular, may be hesitant to disclose proprietary sales figures, though regulators could require summaries by state.

- From a renewable generator's perspective, this approach is less preferred than receiving an allowance, because it would deny them the opportunity to earn revenue from the sale of allowances. 


\subsection{Summary and Conclusions}

Voluntary markets for renewable energy have been growing rapidly in recent years, fueled partly by interest among businesses and consumers in reducing GHG emissions. Currently, these markets provide a convenient way in which consumers can support the development of renewable energy technologies and address the emissions associated with their own electricity consumption. While there are a variety of reasons why consumers purchase green power, GHG benefits have been an important motivator, particularly for nonresidential consumers to date. Going forward, the emerging regulation of $\mathrm{CO}_{2}$ under state and regional cap-and-trade programs has important implications for the viability and future growth of voluntary renewable energy markets.

In an era of carbon regulation, voluntary renewable energy markets can continue to play an important role because many consumers may be interested in supporting investment in renewable energy beyond what is supported through mandates or other types of policy support. Some consumers may not be satisfied that emissions caps or other regulatory actions are sufficient to address the threats of global warming. In addition, many businesses and organizations may not be subject to carbon regulation, but may be interested in taking action to reduce the impacts of their own emissions footprints. Businesses and consumers may want to help support renewable energy today in order to help transform the technology to meet long-term emission-reduction goals. Voluntary markets for renewable energy may also be important because renewables provide advantages beyond no (or low) emissions, such as energy security and economic development benefits.

The design of carbon regulations will have implications for the ability of consumers to affect emissions levels through their green power purchases, however. If cap-and-trade programs are designed and implemented so that renewable energy sources do not reduce $\mathrm{CO}_{2}$ levels below the level of the cap (i.e., through the retirement of allowances or adjusting the level of the cap), then consumer purchases of renewable energy would not affect overall emissions levels, unless they purchased and retired an allowance separately. For residential consumers, in particular, this may be problematic, because they are unlikely to understand these complex market interaction issues and may believe that their purchases of green power from zero- or low-emitting renewable energy sources result in emission reductions. This could also reduce business and institutional interest in purchasing RECs to the extent that they are motivated by GHG benefits.

If renewable energy purchases do not affect overall emission levels, what kinds of claims can be made by large purchasers and marketers? Large corporate or institutional purchasers could claim that they are purchasing renewable energy, without making specific emissions-reductions claims; but this may be unsatisfactory for organizations interested in making public statements about their efforts to address global warming. Marketers might claim that renewable energy is "emissions-free" or, perhaps, that purchasing renewable energy will reduce "your emissions." The latter claim might be made because a purchaser could improve the emissions profile of its power purchases, although it might be considered deceptive because overall carbon levels would not be 
changed. To clarify what types of claims can be made and what type of disclosure is adequate to ensure consumer protection, energy regulators may want to consult with state attorneys general and the Federal Trade Commission.

Under carbon cap and trade, both the methods for setting the emissions cap and for allocating allowances are important for emission-reduction claims. Allocating allowances to renewable energy generators is one way to credit renewable generation with the emissions benefits they provide. A reduction in carbon emissions below the level of the cap can be achieved by retiring an allowance, ensuring that it is not sold to an emitter. A renewable energy marketer could convey an allowance with the sale of renewable energy or RECs, and the retirement of the allowance is a clear basis for making an emissionreduction claim. However, there is no guarantee that the allowances will remain bundled with the RECs, as generators will seek to maximize revenues in all available markets. Other approaches, such as reducing the cap or automatically retiring allowances to account for current and future renewable energy generation, would enable consumers to affect GHG emissions levels with their renewable energy purchases, but would not provide renewable energy generators the option of selling allowances in emissions markets. Thus, policy structures that are best suited for voluntary renewable energy markets are not necessarily the preferred policy options for renewable energy generators.

Some specific policy options that would enable purchasers of renewable energy to affect overall emission-reduction claims include the following.

- Renewable Energy Set-Aside of Allowances. Regulators may set aside a certain percentage of total allowances to be granted for renewable energy, which could then be retired to make claims.

- Output-based allocation. Allowances may be granted to generators based on the quantity of electricity produced by each electric generator under the cap. If renewable energy sources are included in the allocation, the allowances could be retired to lower GHG emissions levels.

- A load-based cap, as under consideration in California, could enable voluntary purchases to affect emissions levels depending on the design details. If the program is designed so that an allowance is required to cover the underlying "null" or generic electricity remaining after RECs are sold into voluntary markets, then voluntary purchases would affect emissions levels.

- Reducing the Cap. Regulators can consider demand for renewable electricity when setting the cap, or periodically reduce the cap to reflect growing demand for renewable electricity. Periodic reductions in the cap could be based on either projected demand or on actual demand after the fact. Because emissions would be reduced accordingly, this would enable claims.

- Retiring Allowances on Behalf of Voluntary Market Demand. Regulators could consider demand for renewable electricity and reduce the number of allowances allocated to emitters accordingly. This method focuses on retiring allowances after the cap is established. Under this approach, allowances are retired to reduce emissions, enabling claims. 
In the absence of these policies, consumers could still affect emissions levels by purchasing a so-called "REC-plus" product in which an allowance would be purchased and retired on their behalf and bundled with renewable energy or RECs. Or a consumer could simply purchase carbon emission allowances without the renewable energy component. Either case would result in a clear, verifiable emission reduction and enable a strong claim. However, a REC-plus product would likely either increase the costs considerably to the end-use consumer, suppressing demand, or reduce the amount of revenue that would go to support renewable energy generation, which would reduce the ability of voluntary markets to support new renewable energy development. The latter approach of simply retiring an allowance would not necessarily lead to near-term support for renewable energy because efficiency improvements at fossil plants may dominate near-term compliance actions.

Because of the substantial overlap in renewable energy and emissions markets, regulators and policymakers need to be cognizant of the policy-interaction issues and market implications of new and emerging policies. The voluntary renewable energy market is growing rapidly and provides a convenient and readily available mechanism for consumers to affect the impacts of their electricity consumption today. However, this market needs credibility, consistency, and the ability to articulate clear benefits in order to continue to provide consumers with a viable option for affecting change. 


\section{References}

Amato, Anthony, 2005. ERG consulting for U.S. EPA Green Power Partnership. E-mail communication, September 26.

Arizona Corporation Commission (ACC), 2006. Docket No. RE-00000C-05-0030, In the Matter of the Proposed Rulemaking for the Renewable Energy Standard and Tariff Rules, Decision No. 69127, November 14. http://www.cc.az.us/utility/electric/res.pdf (accessed March 3, 2007).

Aspen Skiing Company, 2006. "Aspen Skiing Company Makes Largest Purchase of Wind Energy Certificates in the U.S. Ski Industry," Press Release, March 1. http://www.aspensnowmass.com/environment/programs/Wind_Press_Release.pdf

Bird, L. and B. Swezey, 2006. Green Power Marketing in the United States: A Status Report (Ninth Edition), NREL/TP-620-40904. Golden, CO: National Renewable Energy Laboratory, November. http://www.eere.energy.gov/greenpower/resources/pdfs/40904.pdf

Blank, E., L. Bird and B. Swezey, 2002. “A Certificate-Based Approach to Marketing Green Power and Constructing New Wind Energy Facilities." Conference paper prepared for Windpower 2002, June 2-5, 2002, Portland, Oregon.

http://www.eere.energy.gov/greenpower/resources/pdfs/0602 newwind cert.pdf

Bluestein, Joel, Elizabeth Salerno, Lori Bird and Laura Vimmerstedt, 2006.

Incorporating Wind Generation in Cap and Trade Programs. Golden, Colorado: National Renewable Energy Laboratory, July.

http://www.eere.energy.gov/windandhydro/windpoweringamerica/pdfs/wpa/policy cap t rade.pdf

Bogdonoff, Sondra and Jonathan Rubin, 2006. A Primer for Maine: Regional Greenhouse Gas Initiative. Muskie School of Public Service and Margaret Chase Smith Policy Center, October. http://www.umaine.edu/mcsc/reports/RGGIPrimer.pdf

Bristow, Sophy, 2006. "Going Carbon Neutral: The Right Path for Business," article written for CEO Magazine by the Climate Group.

http://www.theclimategroup.org/assets/Ofsetting\%20PDF.pdf

Broekhoff, Derik, 2007. World Resources Institute, Washington, D.C. Email communication, March 7, 2007.

Burtraw, Dallas, Karen Palmer and Danny Kahn, 2005. Allocation of $\mathrm{CO}_{2}$ Emissions Allowances in the Regional Greenhouse Gas Cap-and-Trade Program, Discussion Paper. Washington, DC: Resources for the Future. http://www.rff.org/Documents/RFF-DP-05$\underline{25 . p d f}$ 
California Climate Action Registry, 2006. General Reporting Protocol, Version 2.1, June, p. 34. http://www.climateregistry.org/docs/PROTOCOLS/GRP\%20V2.1.pdf

Chicago Climate Exchange, 2006. "CCX Landfill Methane Emissions Offsets," February. http://www.chicagoclimatex.com/news/publications/pdf/CCX_Landfill_Methane_Offsets .pdf

Chicago Climate Exchange, 2006. "Chicago Climate Exchange Announces Formation of the New York Climate Exchange (NYCX) and the Northeast Climate Exchange (NECX)," March 14. http://www.chicagoclimatex.com/news/press/release_20060314_NYCX.html

Chicago Climate Exchange, 2006. "Chicago Climate Exchange Announces Fourth Consecutive Record Trading Month," May 15. http://www.chicagoclimatex.com/news/press/release_20060515_MayRecord.pdf

Chicago Climate Exchange, 2006. "CCX GHG Emission Offsets From Renewable Energy Systems, ” June. http://www.chicagoclimatex.com/news/publications/pdf/CCX_Renewable_Offsets.pdf

Chicago Climate Exchange, 2006. "The Montreal Climate Exchange is Established," July 12. http://www.chicagoclimatex.com/news/press/release_20060712_Montreal_establish.html

City of Bellingham, 2006. "City of Bellingham leads nation in support of renewable energy by "greening" $100 \%$ of municipal energy use," Press Release July 31. http://www.cob.org/features/2006-07-31-green-power.htm

Collison, Blaine, 2006. U.S. EPA Green Power Partnership. E-mail communication, August 18.

Energy Information Administration, 2006. Voluntary Reporting of Greenhouse Gases 2004, Office of Integrated Analysis and Forecasting, U.S. Department of Energy Washington, DC 20585, March. http://www.eia.doe.gov/oiaf/1605/vrrpt/pdf/0608(04).pdf

European Climate Exchange, 2006. "ECX Volume Update-November," December. http://www.europeanclimateexchange.com/index_flash.php "News" section.

Hanson, C., 2005. "The Business Case for Using Renewable Energy," The World Resources Institute's Corporate Guide to Green Power Markets. Installment 7, December.

Harmon, R. and M. Hirschhorn, 2006. Clearing the Air: The Impact of Carbon Cap and Trade Regulations on Renewable Energy, SOLAR 2006 Conference Proceedings, July.

Holt, E. and R. Wiser, 1999. Understanding Consumer Demand for Green Power. Report prepared for the National Wind Coordinating Committee.

http://www.nationalwind.org/publications/green_power.htm 
Holt, E., R. Wiser, M. Fowlie, R. Mayer, and S. Innis., 2001. Understanding NonResidential Demand for Green Power. National Wind Coordinating Committee, January. http://www.nationalwind.org/publications/green_power.htm

Holt, Edward and Ryan Wiser, 2007. The Treatment of Renewable Energy Certificates, Emissions Allowances, and Green Power Programs in State Renewables Portfolio Standards. Lawrence Berkeley National Laboratory, forthcoming.

Jacobson, D., 2007. "Increasing the Value and Expanding the Market for Renewable Energy and Energy Efficiency with Clean Air Policies," Environmental Law Reporter, 37:10135, February.

Kristiansen, Kjell Olav, 2006. Director Advisory Services, Point Carbon. Email communication October 9.

Lieberman, D., 2007. Center for Resource Solutions, Green-e Program, San Francisco, California, Email communication, March 1, 2007.

Little, Amanda Griscom, 2006. "Gore's Climate-Policy Speech Today At NYU: A Carbon Freeze and a Carbon Tax Proposed." Published on Gristmill at http://gristmill.grist.org/story/2006/9/18/152449/358 (accessed on December 27, 2006).

Litz, Franz, 2007. “Regional Greenhouse Gas Initiative: State's Progress on Nation's First Carbon Cap and Trade Program" Presentation for Environmental Markets Association, February 15.

Moody, Phil, 2006. "Carbon Policies and Renewable Energy Markets- How Might Carbon Regulation Affect Green Power Markets.” Association of Issuing Bodies, December $4^{\text {th }}$. (Presentation at the $11^{\text {th }}$ National Renewable Energy Marketing Conference, San Francisco.)

Morgan, Rick, 2007. District of Columbia Public Service Commission, Email communication with Lori Bird. January 31.

National Association of Attorneys General, 1999. Environmental Marketing Guidelines for Electricity, Environmental Marketing Subcommittee of the Energy Deregulation Working Group. December.

Niermeijer, Peter, 2006. RECS International Secretariat. Email communication October 9.

Ölz, S., Bürger, V. Draeck, M. Rohracher, H., Ruggieri, G. Vrolijk, C. and J. Green. et al. 2006. Report on the Interaction of Green Power Labelling with Renewable Energy

Policies. WP5 Report from the Clean-E Project. August. http://www.eugenestandard.org/mdb/publi/8_CLEANE\%20WP\%205\%20Report\%20(D12)\%20final.pdf (accessed February 21, 2007) 
Opinion Research Corporation, 2006. Renewable Energy Survey, Study \#715268, June 29, 2006. Prepared for National Renewable Energy Laboratory, Golden, Colorado.

Oregon Governor's Advisory Group on Global Warming, 2004. Oregon Strategy for Greenhouse Gas Reductions, December. http://www.oregon.gov/ENERGY/GBLWRM/docs/GWReport-FInal.pdf.

Pennsylvania, 2007. "Draft Proposed CAIR Rulemaking," Pennsylvania Department of Environmental Protection, Air Quality Technical Advisory Committee, January 4. http://www.dep.state.pa.us/dep/subject/advcoun/aqtac/aqtac.html accessed February 22, 2007.

Putt Del Pino, Samantha, 2006. Switching to Green: A Renewable Energy Guide for Office and Retail Companies. World Resources Institute, Washington, D.C., October. http://pdf.wri.org/switching_to_green.pdf

Regional Greenhouse Gas Initiative, 2004. "RGGI Stakeholder Workshop on Allowance Apportionment and Allocation," October 14. Linked as Allocations Workshop Summary at http://www.rggi.org/docs/allocation_summary_10_28_04.pdf.

Regional Greenhouse Gas Initiative, 2006. Model Rule, August 15. Subpart XX-5.3 (d) pp.47-50 http://www.rggi.org/modelrule.htm

Regional Greenhouse Gas Initiative, Undated. "About RGGI.” http://www.rggi.org/about.htm

Regulatory Assistance Project, 2006. "Carbon Caps and the Power Industry: Recent State Activity and the Design Issues for Regulators," IssuesLetter, September. http://www.raponline.org

Salerno, Elizabeth, 2006. American Wind Energy Association. E-mail communication, October 27.

Schneiders, Dr. Thorsten, 2006. Referent for Energiepolitik. Email communication October 9.

Sherry, Christopher, 2007. New Jersey Department of Environmental Protection, Bureau of Sustainable Communities and Innovative Technologies. Email to Lori Bird, February 7.

The Climate Trust, 2005. 2005 Request for Carbon Dioxide Offset Project Proposals. May 24 (revised June 2005).

http://www.climatetrust.org/pdfs/RFPs/Climate\%20Trust\%202005\%20RFP.pdf 
Tom, J., 2007. Rulemaking 06-04-009. California Public Utilities Commission. “Assigned Commissioner's Ruling and Phase 2 Scoping Memo". February. http://www.cpuc.ca.gov/EFILE/RULC/64349.pdf (accessed February 20, 2007)

Trexler, M. and L. Kosloff, 2006. "Selling Carbon Neutrality," The Environmental Forum. March/April.

Union of Concerned Scientists, 2006. "Comments on the draft RGGI model rule," May 22. http://www.rggi.org/docs/ucs.pdf

U.S. EPA, 2003. Office of Air and Radiation. Tools of the Trade: A Guide to Designing and Operating a Cap and Trade Program for Pollution Control. EPA430-B-03-002. June. http://www.epa.gov/airmarkets/international/tools.pdf

U.S. EPA, 2004. Climate Leaders Greenhouse Gas Emissions Inventory Protocol Core Module Guidance: Indirect Emissions from Purchases/Sales of Electricity and Steam, October 2004. Appendix B, eGRID Subregion Emission Rates (2000) http://www.epa.gov/climateleaders/docs/indirectelectricityguidance.pdf, accessed December 18, 2006

U.S. EPA, 2005. State Set-Aside Programs for Energy Efficiency and Renewable Energy Projects under the $\mathrm{NO}_{x}$ Budget Trading Program: A Review of Programs in Indiana, Maryland, Massachusetts, Missouri, New Jersey, New York and Ohio. EPA430-R-03005. Draft Report September 16. http://www.epa.gov/cleanenergy/pdf/eere rpt.pdf

U.S. EPA, 2006. News Release: "Companies Set Aggressive Greenhouse Gas Emissions Reduction Goals," October 12, 2006.

http://yosemite.epa.gov/opa/admpress.nsf/a8f952395381d3968525701c005e65b5/abaf76 a31c93d2e685257205006305cb!OpenDocument

Wisconsin, 2006. Initial Proposed Rulemaking Order, Order of the State of Wisconsin Natural Resources Board Creating Rules, July 28.

https://apps4.dhfs.state.wi.us/admrules/public/Rmo?nRmoId=609 accessed February 22, 2007.

Wiser, Ryan, 2007. Lawrence Berkeley National Laboratory, email communication, February 8.

World Resources Institute, 2004. The Greenhouse Gas Protocol: A Corporate Accounting and Reporting Standard, Revised Edition. Washington, D.C.

Wooley, D. R. and E. M. Morss, 2001 Clean Air Act Amendments of 1990: Opportunities for Promoting Renewable Energy, Golden, CO: National Renewable Energy Laboratory SR-620-29448, January. 


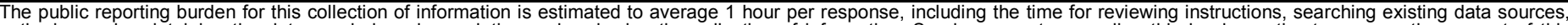

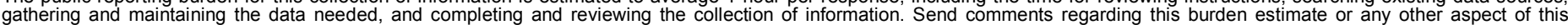

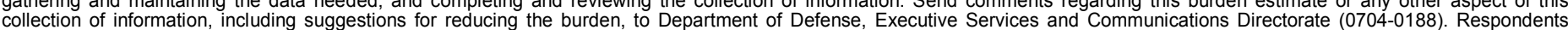

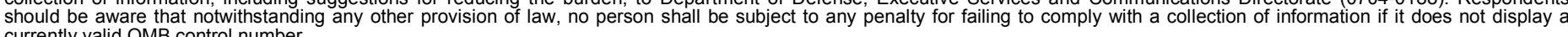

PLEASE DO NOT RETURN YOUR FORM TO THE ABOVE ORGANIZATION.

\begin{tabular}{l|l|l|l} 
1. REPORT DATE $(D D-M M-Y Y Y Y)$ & 2. REPORT TYPE & 3. DATES COVERED (FrOm - TO)
\end{tabular}

April 2007

Technical Report

4. TITLE AND SUBTITLE
Implications of Carbon Regulation for Green Power Markets

5a. CONTRACT NUMBER

DE-AC36-99-GO10337

5b. GRANT NUMBER

5c. PROGRAM ELEMENT NUMBER

6. AUTHOR(S)

Lori Bird, Ed Holt, and Ghita Carroll

5d. PROJECT NUMBER

NREL/TP-640-41076

5e. TASK NUMBER

ASG6.1005

5f. WORK UNIT NUMBER
7. PERFORMING ORGANIZATION NAME(S) AND ADDRESS(ES)

National Renewable Energy Laboratory

1617 Cole Blvd.

Golden, CO 80401-3393

9. SPONSORING/MONITORING AGENCY NAME(S) AND ADDRESS(ES)
8. PERFORMING ORGANIZATION REPORT NUMBER

NREL/TP-640-41076

10. SPONSOR/MONITOR'S ACRONYM(S) NREL

11. SPONSORING/MONITORING AGENCY REPORT NUMBER

\section{DISTRIBUTION AVAILABILITY STATEMENT}

National Technical Information Service

U.S. Department of Commerce

5285 Port Royal Road

Springfield, VA 22161

13. SUPPLEMENTARY NOTES

14. ABSTRACT (Maximum 200 Words)

This paper examines the potential effects that emerging mandatory carbon markets have for voluntary markets for renewable energy, or green power markets. In an era of carbon regulation, green power markets will continue to play an important role because many consumers may be interested in supporting renewable energy development beyond what is supported through mandates or other types of policy support. The paper examines the extent to which GHG benefits motivate consumers to make voluntary renewable energy purchases and summarizes key issues emerging as a result of these overlapping markets, such as the implications of carbon regulation for renewable energy marketing claims, the demand for and price of renewable energy certificates (RECs), and the use of RECs in multiple markets (disaggregation of attributes). It describes carbon regulation programs under development in the Northeast and California, and how these might affect renewable energy markets in these regions, as well as the potential interaction between voluntary renewable energy markets and voluntary carbon markets, such as the Chicago Climate Exchange (CCX). It also briefly summarizes the experience in the European Union, where carbon is already regulated. Finally, the paper presents policy options for policymakers and regulators to consider in designing carbon policies to enable carbon markets and voluntary renewable energy markets to work together.

\section{SUBJECT TERMS}

carbon regulation; climate change; green power; renewable energy markets; renewable energy certificates; RECs; voluntary markets; greenhouse gas emissions; climate policy

\begin{tabular}{|c|c|c|}
\hline \multicolumn{3}{|c|}{ 16. SECURITY CLASSIFICATION OF: } \\
\hline $\begin{array}{l}\text { a. REPORT } \\
\text { Unclassified }\end{array}$ & $\begin{array}{l}\text { b. ABSTRACT } \\
\text { Unclassified }\end{array}$ & $\begin{array}{l}\text { c. THIS PAGE } \\
\text { Unclassified }\end{array}$ \\
\hline
\end{tabular}

\begin{tabular}{l|l}
$\begin{array}{l}\text { 17. LIMITATION } \\
\text { OF ABSTRACT }\end{array}$ & $\begin{array}{l}\text { 18. } \\
\text { NUMBER } \\
\text { OF PAGES }\end{array}$ \\
&
\end{tabular}

19a. NAME OF RESPONSIBLE PERSON

19b. TELEPHONE NUMBER (Include area code) 